\title{
Modelling large-scale ice-sheet-climate interactions following glacial inception
}

\author{
J. M. Gregory ${ }^{1,2}$, O. J. H. Browne ${ }^{1}$, A. J. Payne ${ }^{3}$, J. K. Ridley ${ }^{2}$, and I. C. Rutt ${ }^{4}$ \\ ${ }^{1}$ NCAS-Climate, Department of Meteorology, University of Reading, Reading, UK \\ ${ }^{2}$ Met Office Hadley Centre, Exeter, UK \\ ${ }^{3}$ School of Geographical Sciences, University of Bristol, Bristol, UK \\ ${ }^{4}$ Department of Geography, College of Science, Swansea University, Swansea, UK
}

Correspondence to: J. M. Gregory (j.m.gregory@ reading.ac.uk)

Received: 7 December 2011 - Published in Clim. Past Discuss.: 9 January 2012

Revised: 5 September 2012 - Accepted: 14 September 2012 - Published: 11 October 2012

\begin{abstract}
We have coupled the FAMOUS global AOGCM (atmosphere-ocean general circulation model) to the Glimmer thermomechanical ice-sheet model in order to study the development of ice-sheets in north-east America (Laurentia) and north-west Europe (Fennoscandia) following glacial inception. This first use of a coupled AOGCM-ice-sheet model for a study of change on long palæoclimate timescales is made possible by the low computational cost of FAMOUS, despite its inclusion of physical parameterisations similar in complexity to higher-resolution AOGCMs. With the orbital forcing of $115 \mathrm{ka}$ BP, FAMOUS-Glimmer produces ice caps on the Canadian Arctic islands, on the north-west coast of Hudson Bay and in southern Scandinavia, which grow to occupy the Keewatin region of the Canadian mainland and all of Fennoscandia over $50 \mathrm{ka}$. Their growth is eventually halted by increasing coastal ice discharge. The expansion of the icesheets influences the regional climate, which becomes cooler, reducing the ablation, and ice accumulates in places that initially do not have positive surface mass balance. The results suggest the possibility that the glaciation of north-east America could have begun on the Canadian Arctic islands, producing a regional climate change that caused or enhanced the growth of ice on the mainland. The increase in albedo (due to snow and ice cover) is the dominant feedback on the area of the ice-sheets and acts rapidly, whereas the feedback of topography on SMB does not become significant for several centuries, but eventually has a large effect on the thickening of the ice-sheets. These two positive feedbacks are mutually reinforcing. In addition, the change in topography perturbs the tropospheric circulation, producing some reduction
\end{abstract}

of cloud, and mitigating the local cooling along the margin of the Laurentide ice-sheet. Our experiments demonstrate the importance and complexity of the interactions between icesheets and local climate.

\section{Introduction}

The repeated formation, advance, retreat and disappearance of extensive Northern Hemisphere (NH) ice-sheets is the defining characteristic of the glacial cycles of the Pleistocene. Ice-sheets are very sensitive to climate change through its effect on their surface mass balance (SMB) i.e. accumulation (mostly snowfall) minus surface ablation (mostly melting followed by runoff); they feed back on regional and global climate change through their effects on surface characteristics and altitude, and freshwater runoff into the ocean. Understanding in detail the enormous and complex changes in climate and ice-sheets which take place during glacial cycles is an important challenge of Earth system science, and a crucial source of information about how icesheets may respond to anthropogenic climate change.

It is generally accepted that glacial cycles arise from variations in insolation that result from changes in the orientation of the Earth's axis of rotation and in its orbit around the sun (referred to as "orbital parameters"). However, the magnitude of the resulting climate change is greatly magnified by feedback from changes in ice-sheets and the concentration of greenhouse gases in the atmosphere (e.g. Hewitt and Mitchell, 1997). Various authors have studied the 
conditions necessary for glacial inception, i.e. the start of icesheet growth in the Northern Hemisphere (Dong and Valdes, 1995; Yoshimori et al., 2002; Khodri et al., 2003; Vettoretti and Peltier, 2003; Calov et al., 2005; Otieno and Bromwich, 2009; Born et al., 2010). The focus of the present work is on the effect of ice-sheet-climate interactions on the growth of the ice-sheets following glacial inception.

This study requires a coupled ice-sheet-climate model. The type of climate model containing the most complete and detailed representation of the physical processes relevant to ice-sheet-climate interactions is the threedimensional coupled atmosphere-ocean general circulation model (AOGCM). Owing to their computational expense, the state-of-the-art AOGCMs used for climate change prediction simulate only a few years per day when using hundreds of CPU cores. Consequently, studies of the evolution of ice-sheets using AOGCMs coupled to ice-sheet models have been limited to considering a few millennia at most (Ridley et al., 2005; Vizcaíno et al., 2008, 2010).

Three simplified approaches have therefore been followed in previous work on ice-sheet evolution on multimillennial timescales during glacial cycles. These approaches are discussed in greater detail in the informative review by Pollard (2010). One approach (Marshall et al., 2002; Charbit et al., 2002; Zweck and Huybrechts, 2005; Tarasov and Peltier, 2006; Abe-Ouchi et al., 2007) is to use an ice-sheet model alone, forced by a prescribed time-dependent climate that is estimated by interpolating between short, steady-state atmosphere GCM simulations for different prescribed icesheet sizes and other forcing factors. This method limits the number of degrees of freedom that can be represented in ice-sheet-climate interaction. Another approach (Wang and Mysak, 2002; Kageyama et al., 2004; Calov et al., 2005, 2009; Charbit et al., 2005; Bonelli et al., 2009; Ganopolski et al., 2010; Fyke et al., 2011) is to use an ice-sheet model interactively coupled to a climate model of reduced complexity. Such models simplify the representation of atmospheric dynamics and thermodynamics in a variety of ways which may affect the simulation of relevant feedback, for example moisture transport, cloudiness and precipitation. A third approach (Ridley et al., 2010; Herrington and Poulsen, 2012) is to run the ice-sheet model continuously, coupled to an atmosphere GCM or AOGCM, which is run for short periods separated by hundreds or thousands of years. Because the ice-sheet model SMB and the climate model topography and surface conditions are updated rather infrequently, the evolution may show abrupt changes in some quantities.

In the present work, which extends that of Browne (2009), we follow an approach between the second and the third: we couple an ice-sheet model interactively and frequently to a low-resolution AOGCM. This runs quickly enough that multimillennial simulations are feasible, while retaining the range of interactive processes included in typical AOGCMs used for climate projection. Because this is a new model, we have chosen a limited focus in the present work, namely on the interaction, following glacial inception, of the ice-sheets developing in particular regions with the global atmosphere and surface climate. Because of this focus, although our model integrations are many thousands of years long, we fix the boundary conditions (orbital forcing, atmospheric composition, sea-level, coastline and bedrock altitude), as described in following sections. Thus, we do not attempt to produce a comprehensive simulation of actual evolution of the ice-sheets during the last glacial cycle. That purpose would require model developments which are not yet available.

The focus of this work requires the capacity to simulate the various effects of ice-sheets on their regional climate. The high surface albedo of ice and snow tends to reduce the absorbed solar radiation. Thickening of the ice-sheet increases its surface altitude. At higher altitude, surface air temperature is usually lower, and this will tend to reduce surface melting by sensible heating and net downward longwave radiation. Cloudiness and precipitation also depend on altitude, but the relationships are geographically dependent and may have either sign. An ice-sheet may cool the air blowing over it and thus cool surrounding ice-free areas. The emergence of new topography as the ice-sheet grows may influence the largescale atmospheric circulation, with consequent local and regional effects on many aspects of climate. All of these mechanisms are represented in our model, to the extent permitted by the approximations of spatial resolution and physical schemes.

\section{Simulation of recent and incipient glacial climates}

We employ the FAMOUS AOGCM (version name ADTAN, http://www.famous.ac.uk, Jones et al., 2005), which is a lowresolution version of the extensively used HadCM3 AOGCM (Gordon et al., 2000). The HadCM3 simulation of presentday climate is of comparable realism to many more recently developed AOGCMs (Reichler and Kim, 2008). FAMOUS has a grid-spacing of $3.75^{\circ} \times 2.5^{\circ}$ and 20 levels in the ocean, and $7.5^{\circ} \times 5^{\circ} \times 11$ levels in the atmosphere. The atmosphere timestep is $1 \mathrm{~h}$ and the ocean timestep $12 \mathrm{~h}$. Structurally, FAMOUS is almost identical to HadCM3, and produces climate and climate-change simulations which are reasonably similar to HadCM3, but runs about ten times faster. It is therefore a suitable model for climate experiments involving long or many integrations and it is continuing to be improved. Smith and Gregory (2012) have recently used a later version of FAMOUS (Smith et al., 2008) to carry out transient simulations of the whole of the last glacial cycle but with time-dependent ice-sheets prescribed as a boundary condition, rather than interactively simulated. They evaluated the simulations by comparison with proxy evidence, finding that FAMOUS performs well on several measures.

We carry out simulations for two climates: the Holocene at the start of the industrial revolution (which we will refer to as "recent"), and the climate during which ice-sheets were first 
growing (called "incipient glacial" or "IG"). For the recent climate we use present-day orbital parameters. For the incipient glacial climate we use fixed orbital parameters applicable to $115 \mathrm{ka} \mathrm{BP}$, when summer top-of-atmosphere (TOA) insolation at the latitudes of Northern Hemisphere ice-sheets was at a minimum; in June it was $33 \mathrm{~W} \mathrm{~m}^{-2}$ less than in the recent climate averaged over $50-75^{\circ} \mathrm{N}$. Reduced summer insolation is favourable for ice-sheet growth, and studies of glacial inception (such as cited above) have likewise chosen 115 or $116 \mathrm{ka}$ BP.

All our simulations have interglacial atmospheric composition fixed as it was early in the industrial revolution, as normally represented in FAMOUS $\left(\mathrm{CO}_{2} 290 \mathrm{ppm}\right.$ by volume, $\mathrm{CH}_{4} 793 \mathrm{ppb}, \mathrm{N}_{2} \mathrm{O} 285 \mathrm{ppb}$; for comparison, the $\mathrm{CO}_{2}$ concentration of $115 \mathrm{ka} \mathrm{BP}$ was about $270 \mathrm{ppm}$ ). We also fix the Greenland and Antarctic ice-sheets with their present-day extent and topography as normally represented in FAMOUS. Thus, the only difference of boundary conditions between the two times of interest is the orbital forcing.

For each climate, we carried out a FAMOUS-only integration, without Glimmer and without Laurentide and Fennoscandian ice-sheets (for reference, Table 1 lists all the FAMOUS experiments we analyse in this paper). The two integrations were initialised from the same FAMOUS state and were run for $700 \mathrm{yr}$. Since this starting state was obtained from a different version of FAMOUS, both integrations exhibit fairly rapid initial climate drift, which diminishes to a small value during the first $300 \mathrm{yr}$. During the remaining $400 \mathrm{yr}$, the TOA net radiation, which indicates the energy imbalance of the climate system, is within $0.1 \mathrm{~W} \mathrm{~m}^{-2}$ of zero in both integrations, which is small compared with the global-mean orbital forcing difference, due to reduced orbital eccentricity, of $0.74 \mathrm{~W} \mathrm{~m}^{-2}$ between incipient glacial and recent. The rate of change of global-mean SAT (surface air temperature) is fairly constant in each integration, at +0.10 and $-0.15 \mathrm{~K} \mathrm{ka}^{-1}$ respectively for recent and incipient glacial. The Antarctic Dome $\mathrm{C}$ deuterium record of EPICA Community Members (2004) indicates that SAT was $0.9 \mathrm{~K}$ lower than present at $120 \mathrm{ka} \mathrm{BP}$, while by $110 \mathrm{ka} \mathrm{BP}$ it was $5.5 \mathrm{~K}$ lower than present, equivalent to a rate of cooling of about $0.5 \mathrm{~K} \mathrm{ka}^{-1}$ during the glacial inception. The simulated climate drift is tolerably small compared with this. We thus consider both FAMOUS climates to be steady after $300 \mathrm{yr}$.

The climatology of FAMOUS version ADTAN for recent conditions is evaluated by Jones et al. (2005). Its most notable error is a cold bias in annual-mean SAT and associated excessive sea-ice cover in high northern latitudes (Fig. 3 of Jones et al., 2005); HadCM3 has a qualitatively similar but smaller bias. Obviously this bias is relevant to glacial inception at these latitudes (cf. Vettoretti and Peltier, 2003), but it is most pronounced in winter, and it is smaller in summer, the season when SAT will affect ablation. We discuss the effect of this bias in Sect. 4.3. The bias could be counteracted by targeted adjustment of model parameters,but this could be deleterious to the simulation of the incipient glacial climate (Smith et al., 2008; Gregoire et al., 2011). Similarly, flux adjustment of the AOGCM or anomaly coupling to the ice-sheet model (e.g. Lunt et al., 2004; Ridley et al., 2005; Vizcaíno et al., 2008) could be used to compensate for the bias, but these techniques depend on the assumption that climate change is small enough to be considered a linear perturbation, which will not be true for the large changes in local climate that develop as a result of growth of ice-sheets (Sect. 5).

Global-mean SAT is slightly warmer in the incipient glacial climate than in the recent climate: for years 301-400 it is $287.26 \pm 0.03 \mathrm{~K}$ and $286.95 \pm 0.03 \mathrm{~K}$, respectively. This is consistent with the positive global-mean orbital forcing in the incipient glacial climate and is a simple demonstration that global-mean radiative forcing or SAT cannot predict glacial inception. The relevant indicators are the much larger latitudinally and seasonally dependent changes in zonal-mean surface air temperature of either sign (Fig. 1), corresponding to the changes in TOA insolation, lagged by about a month due to thermal inertia and the persistence of sea-ice. Cooling in $50-75^{\circ} \mathrm{N}$ is greatest in July, warming in April, extending over all longitudes, but most pronounced over land.

For a further comparison, we have produced a simulation of the incipient glacial climate using the HadSM3 climate model, which comprises the HadCM3 atmosphere coupled to a "slab" ocean of $50 \mathrm{~m}$ depth with the same grid-spacing as the atmosphere, and heat convergence calibrated for the recent climate. This model has been used in previous studies of the climate of the Last Glacial Maximum (Hewitt et al., 2003) and the Holocene (Brayshaw et al., 2010). HadSM3 has higher atmosphere resolution than FAMOUS and smaller biases in its simulation of recent climate, on account of the slab ocean heat convergence. Nonetheless, HadSM3 and FAMOUS are largely similar in the patterns of the simulated differences between the incipient glacial and recent climates. Both show low-latitude warming in the annual mean, and pronounced cooling in mid- to high northern latitudes in summer (Fig. 2).

\section{Coupled ice-sheet-climate model}

\subsection{The ice-sheet model}

We use the Glimmer ice-sheet model (version 1.0.4), which was based on the 3-D thermomechanical model of Payne (1999), was developed at the Universities of Bristol and Edinburgh (Rutt et al., 2009), and is now an open-source project (http://developer.berlios.de/projects/glimmer-cism). We use the shallow ice approximation for ice-sheet dynamics. This is not adequate for simulation of ice-streams, but that is not a serious concern because we expect the ice-sheets to be frozen at the bed during the early stages of glaciation. The model formulation permits the ice-sheet to advance into shallow 
Table 1. List of FAMOUS experiments discussed in this work. The notation $1: n$ indicates an asychronous integration with $n$ Glimmer icesheet years for each FAMOUS climate year; in this notation, the synchronous integrations are 1: 1. "Recent" and "IG" ("incipient glacial") identify the climate conditions, and for each FAMOUS-Glimmer experiment the range of Glimmer years is shown. The two FAMOUS-only experiments were $400 \mathrm{yr}$ long, preceded by $300 \mathrm{yr}$ of spin-up.

\begin{tabular}{lrr}
\hline & \multicolumn{2}{c}{ Glimmer years } \\
\cline { 2 - 3 } Model configuration & Recent & IG \\
\hline FAMOUS-only & none & none \\
FAMOUS-Glimmer synchronous & $1-500$ & $1-500$ \\
FAMOUS-Glimmer $1: 10$ & $1-35000$ & $1-25000$ \\
FAMOUS-Glimmer 1: 100 & - & $10000-60000$ \\
FAMOUS-Glimmer $1: 10$ no albedo feedback & - & $1-10000$ \\
FAMOUS-Glimmer $1: 10$ no topography feedback & - & $1-12000$ \\
\hline
\end{tabular}

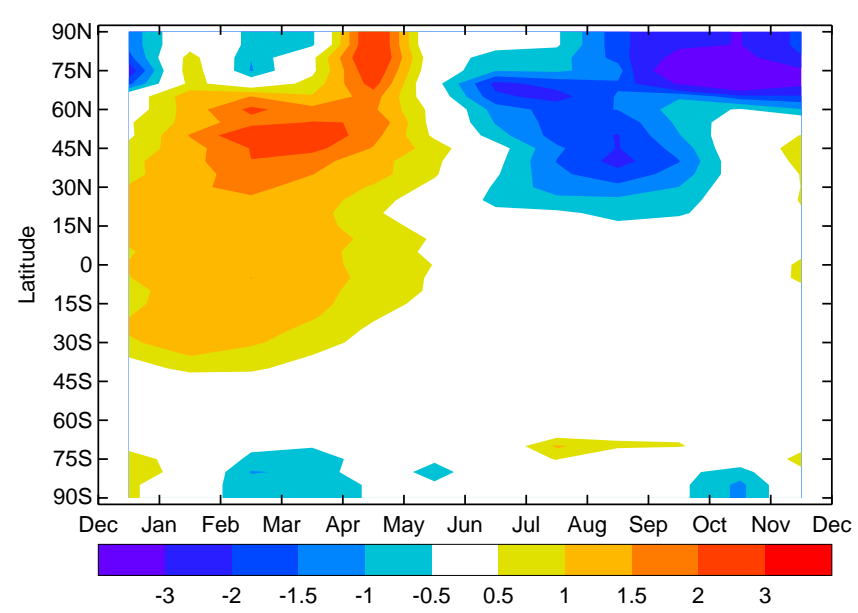

Fig. 1. Difference between $115 \mathrm{ka} \mathrm{BP}$ (incipient glacial) and recent conditions (IG minus recent) as a function of latitude and time of year in climatological surface air temperature in years 301-330 of the FAMOUS-only experiments.

water, using a threshold water depth or a flotation criterion to determine the limit of grounded ice. With either treatment, the position of the margin is mostly determined by sea-level, which is fixed in our experiments. To simulate the advance of ice beyond the present-day coastline, the model would need global-mean sea-level change as a boundary condition (Huybrechts, 2002) and a dynamical treatment of ice-shelves and the grounding line.

Glimmer can run in several discontiguous domains simultaneously. Making use of this facility, we define two separate Glimmer grids with square gridboxes of an area of $20 \times 20 \mathrm{~km}^{2}$ on Lambert azimuthal equal-area projection planes, to cover two commonly accepted regions of icesheet inception in the north-east of Canada and in Scandinavia, which we call the "Laurentia" and "Fennoscandia" domains, respectively. The former is centred over Baffin Island at $278^{\circ} \mathrm{E}$ and $71.5^{\circ} \mathrm{N}$, with 150 gridboxes in $x$ and 160 in $y$, the latter in Sweden at $17.5^{\circ} \mathrm{E}$ and $63.5^{\circ} \mathrm{N}$, with 130 gridboxes in $x$ and 125 in $y$. We choose these two regions

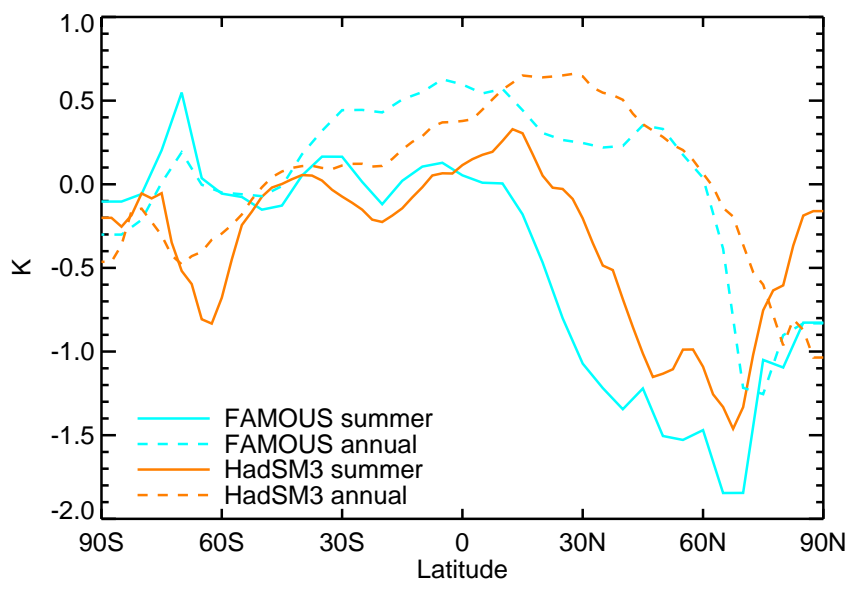

Fig. 2. Zonal-mean surface air temperature difference between the annual and summer (JJA) means of the incipient glacial and recent climates of FAMOUS and HadCM3.

because they are among those in which glacial inception is likely (see also Sect. 4.4), and are therefore suitable areas for studying ice-sheet-climate interaction.

We run Glimmer with $11 \sigma$-levels, using a timestep of $0.5 \mathrm{yr}$. In both domains, we initialise Glimmer as ice-free with present-day (bedrock) topography from the ETOPO2 dataset (http://www.ngdc.noaa.gov/mgg/fliers/ 01mgg04.html, edition of 2001), which is on a $2^{\prime}$ grid. In order to simplify the analysis of climate feedback, isostatic adjustment is switched off. Through its effect on topography on its characteristic multimillennial timescale, isostatic adjustment affects regional climate, and it should be included for a fully realistic simulation.

\subsection{Simulation of surface mass balance}

We calculate SMB from FAMOUS monthly-mean SAT and precipitation using an annual positive-degree-day (PDD) scheme, which is a convenient and well-established approach for studies of past, present and future ice-sheets (e.g. Reeh, 
1989; Huybrechts et al., 1991; Braithwaite, 1995; van den Broeke et al., 2010; Huybrechts et al., 2011; Herrington and Poulsen, 2012). This is an empirical scheme, with parameters determined for present-day climate, and may therefore be less reliable in other climates than a method which explicitly considered energy balance and the separate influence of variables such as solar radiation and wind (see also Sect. 6).

In the PDD scheme, the potential ablation (the melting which would occur if there were no limit on the amount of snow and ice remaining to be melted) is $f D$, where $f$ is a degree-day factor $\left(8.0 \mathrm{~mm} \mathrm{~d}^{-1} \mathrm{~K}^{-1}\right.$ liquid water equivalent for ice and 3.0 for snow) and $D$ is the time-integral of the excess of $T$ over freezing point, $D=\int \max (0, T(t)-$ $\left.T_{\text {freezing }}\right) \mathrm{d} t$. The Glimmer scheme makes a simple allowance for meltwater refreezing in the snowpack ( $60 \%$ of the annual accumulation refreezes before runoff is produced).

Because we require sufficient spatial resolution to represent the pronounced gradients of SMB in areas of mountainous topography, which are important for glacial inception, and across steep ice-sheet margins, which have a width of tens of kilometres, SMB is computed on the Glimmer grid. This bilinearly interpolates the temperature and precipitation data from the lower-resolution FAMOUS atmosphere grid, and adjusts the temperature to the Glimmer topography using a lapse rate of $8 \mathrm{~K} \mathrm{~km}^{-1}$, which lies between the freetropospheric dry and saturated adiabatic lapse rates. In reality the lapse rate varies in space and time, and the surfaceair lapse rate may differ from the free-troposphere lapse rate (Marshall et al., 2007; Gardner and Sharp, 2009). Precipitation is not adjusted for elevation, and all precipitation is assumed to fall as snow in Glimmer, even when it is rainfall in FAMOUS.

In the annual PDD scheme, $T$ is assumed to follow a sinusoidal annual cycle, parametrised from monthly means, with random variations from the cycle, normally distributed with standard deviation $\sigma_{\mathrm{dd}}$, representing the effects of variability on all subannual timescales. To choose an appropriate $\sigma_{\mathrm{dd}}$, we use $100 \mathrm{yr}$ of SAT from the FAMOUS incipient glacial climate, and evaluate $D$ at each Glimmer gridpoint both from hourly data and from the annual cycle as parametrised by the annual scheme. We adopt $\sigma_{\mathrm{dd}}=2.8 \mathrm{~K}$ and $3.1 \mathrm{~K}$ for Fennoscandia and Laurentia respectively, since these values give the smallest differences in the domain averages between the two calculations of $D$. These are close to the summer values, because this is when ablation predominantly occurs, although the variability is more than twice as large in winter, as expected in mid-latitudes.

The simplifications of the SMB scheme and the choice of empirical parameters introduce systematic uncertainties. SMB is strongly sensitive to $\sigma_{\mathrm{dd}}$, with $\pm 100 \%$ variation over the range 3-8 K, and variations of tens of percents result from varying the degree-day factors, refreezing fraction and lapse rate within plausible ranges.

In the coupled model, FAMOUS and Glimmer have independent simulations of surface mass balance and runoff. The

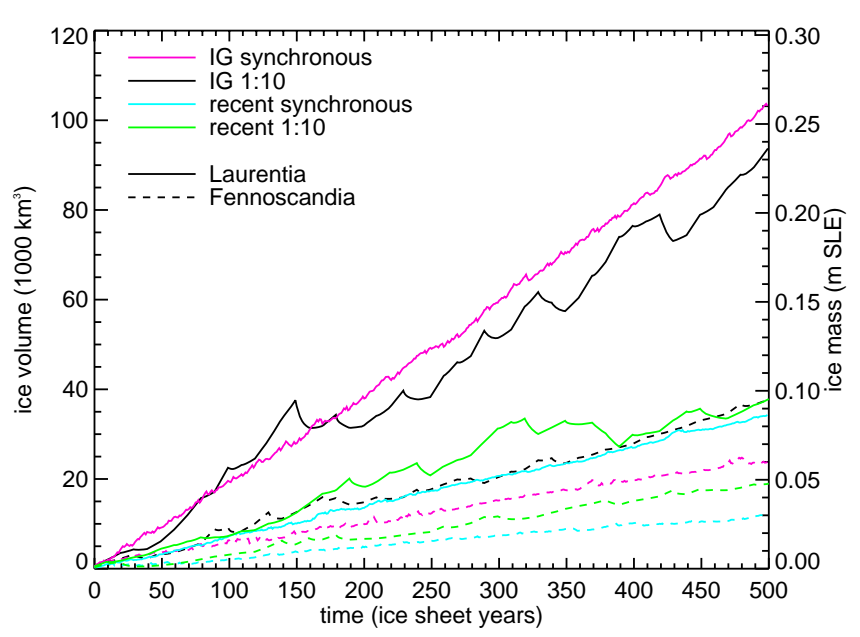

Fig. 3. Ice-sheet mass as a function of time for the first $500 \mathrm{yr}$ of the synchronous and asychronous $(1: 10)$ experiments. Glimmer domains are indicated by linestyle, and experiments by colour. Values are annual means.

Glimmer simulation, described in this section, is an input to the evolution of the ice-sheets only. The FAMOUS land surface scheme separately computes the snow cover, which is an input to the radiation and boundary layer schemes, indirectly affected by Glimmer through the modification of land surface characteristics (described in the next section). The two simulations of SMB are inconsistent regarding energy and mass, as is the case in many such coupled models; eliminating this inconsistency is one of the motivations for further model development (Sect. 6).

The FAMOUS ocean receives runoff from the FAMOUS land surface scheme, not from Glimmer. In particular, solid discharge from the ice-sheet (calving) is not applied to the ocean. This excludes an ice-sheet-climate interaction which could be important, for instance in Heinrich events, although not in the incipient glacial period.

\subsection{Evolution of topography and land surface characteristics}

As the area and volume of the ice-sheets evolve, they modify the topography and other characteristics of the land surface. This is an essential part of ice-sheet-climate interaction. In coupled FAMOUS-Glimmer we use similar methods to those of Ridley et al. (2005), whereby the FAMOUS surface is updated once per year to make it consistent with the Glimmer ice-sheets. The coupling code calculates various statistics of the Glimmer topography within each FAMOUS atmosphere gridbox (mean, standard deviation and mean magnitude of horizontal derivatives), used by atmosphere dynamics, boundary layer and gravity wave drag schemes. These properties are updated for all FAMOUS gridboxes which lie completely within the Glimmer domain. 
For each such FAMOUS gridbox, the coupling code also evaluates the fraction of the land area having ice cover according to Glimmer. (We count a Glimmer gridpoint as icecovered if it has $>0.2 \mathrm{~kg} \mathrm{~m}^{-2}$ of ice.) If its ice-covered fraction is not zero, the coupling code deems it to be an icesheet gridbox in FAMOUS; if the fraction is zero, it is an ice-free gridbox. Various properties of the land surface are changed if a gridbox is converted from ice-free to ice-sheet or vice-versa, the most important being that ice-sheet gridboxes have a snow-free albedo of 0.75 , while gridboxes from which ice has retreated are assigned a snow-free albedo of 0.15 , appropriate to a dark coarse-grained soil. Changing the snow-free albedo when ice cover appears or disappears in a gridbox gives a positive feedback on advance or retreat of the ice-sheet, because higher albedo tends to cool the gridbox and lower albedo to warm it. The coupling code maximises this feedback, because the development of ice cover at a single Glimmer gridpoint is sufficient to convert an entire FAMOUS gridbox to an ice-sheet gridbox. We made this choice by design in these experiments in order to promote ice-sheet growth. In Sect. 5.3 we consider the opposite extreme of minimising the albedo feedback by suppressing it altogether.

\section{FAMOUS-Glimmer simulation of ice-sheet growth}

\subsection{The first $500 \mathrm{yr}$}

Integrations of the coupled FAMOUS-Glimmer for both climates began from year 401 of the corresponding FAMOUSonly integrations, $100 \mathrm{yr}$ after a nearly steady-state climate had been achieved. There is no perennial accumulation of snow in FAMOUS at any gridbox except in Greenland and Antarctica in either climate, but Glimmer simulates positive SMB in some parts of its domain. As a result of the deliberately exaggerated land-surface feedback in the coupling (Sect. 3.3), FAMOUS gridboxes containing Glimmer gridpoints with positive SMB are converted to ice-sheet gridboxes. Within the first two decades, the ice-sheet area in FAMOUS thus expands to the size it maintains for many centuries, but because of interannual fluctuation in regional climate, some GCM gridboxes around the margin of the affected area alternate continually between land-ice and icefree states, giving rise to variability in the ice-sheet area.

In both climates, ice builds up at an almost steady rate over the first $500 \mathrm{yr}$ (see synchronous experiments in Fig. 3), implying that the net ice-sheet-climate feedback on SMB changes little during this period. In Fennoscandia, the rate of growth of ice is about twice as large in the incipient glacial climate as in the recent climate, and in Laurentia about three times as large (compare the magenta lines with the cyan lines), clearly demonstrating the sensitivity of SMB to orbital forcing. In both the Glimmer domains, both FAMOUS and HadSM3 show summer cooling which is statistically signifi- cant in a $5 \%$ two-tailed t-test (Fig. 4), assuming years to be independent and using the FAMOUS estimate of variance; in contrast, the change in precipitation is not significant. Otieno and Bromwich (2009) also find that summer temperature is more important than precipitation for inception in Laurentia.

\subsection{Asynchronous coupling}

The rate of growth of ice mass (Table 2) suggests that the build-up of ice equivalent to tens of metres of sea level would require tens of millennia. Although fast for an AOGCM, FAMOUS would take 100 days to simulate $10 \mathrm{ka}$. To make it practical to carry out several experiments of such a length, we need to accelerate the ice-sheet evolution. Since Glimmer is only a small fraction of the computational cost of FAMOUSGlimmer, we can conveniently achieve an acceleration by a factor of $n$ by using each year of annual-mean SMB computed from FAMOUS as input for simulating $n$ consecutive years of ice-sheet evolution. That is, the experiment has $n$ ice-sheet years for each climate year; we call this "asynchronous $1: n$ coupling”. Following Ridley et al. (2005), who successfully used this technique in a coupled simulation of the Greenland ice-sheet with HadCM3, we choose $n=10$ for the initial growth of the ice-sheets, and $n=100$ to reach the final steady state. Provided the ice-sheet topography does not change enough within a coupling interval to make a difference to the climate which would be significant compared with unforced variability we do not expect this asynchronous coupling to substantially affect ice-sheet-climate interaction. Support for this is given by Calov et al. (2009), who show relatively small effects for $n=10$ and $n=100$. On the other hand, Calov et al. and Herrington and Poulsen (2012) show substantial dependence of results for ice-sheet inception for less frequent coupling, with $n \geq 500$. Even with acceleration, information exchange between FAMOUS and Glimmer occurs many times per wall-clock day and hundreds of times or more in total during multimillennial experiments; therefore it is essential for the coupling to be automated.

In the synchronous experiment, the mass $M_{\mathrm{s}}$ of either icesheet after time $t$ is $M_{\mathrm{S}}=\sum_{t^{\prime}=1}^{t} S_{\mathrm{s}}\left(t^{\prime}\right)$, where $S_{\mathrm{S}}(t)$ is the SMB for the ice-sheet for year $t$ and the sum is over years. (Ice discharge into the sea is negligible in the early centuries, Sect. 5.2.) Although the time-mean $S_{\mathrm{s}}$ is positive and determines the trend in $M_{\mathrm{s}}$, unforced climate variability means that $S_{\mathrm{S}}$ varies slightly from year to year, so $M_{\mathrm{S}}(t)$ is not a perfectly straight line. In the asynchronous experiment, the mass after ice-sheet year $t$ is $M_{\mathrm{a}}=\sum_{t^{\prime}=1}^{t / n} n S_{\mathrm{a}}\left(t^{\prime}\right)$ where the sum is over climate years. The factor $n$ multiplying each $S_{\text {a }}$ magnifies the effect of unforced climate variability.

The rate of growth of ice appears to be different in the asynchronous from the synchronous experiments (compare magenta with black and cyan with green in Fig. 3 and Table 2). However, there are ten times fewer degrees of freedom in the asynchronous timeseries. To decide whether the evolution is significantly different in a statistical sense, we have to 
Table 2. Ice-sheet mass $M$ and rates of growth $\mathrm{d} M / \mathrm{d} t$ at various times throughout the experiments for the recent and incipient glacial ("IG") climates. "L" and "F" stand for the Laurentia and Fennoscandia Glimmer domains. The notation $1: n$ indicates an asychronous integration with $n$ ice-sheet years for each climate year; in this notation, the synchronous integrations are $1: 1$. The Kolmogorov statistic, which is dimensionless, is used to compare the SMB in the corresponding synchronous and asynchronous integrations, as explained in the text. To convert ice mass in units of metres of sea-level equivalent (m SLE) to ice volume in units of $10^{6} \mathrm{~km}^{3}$, divide by 2.53 .

\begin{tabular}{|c|c|c|c|c|}
\hline & \multicolumn{2}{|c|}{ recent } & \multicolumn{2}{|c|}{ IG } \\
\hline & $\mathrm{L}$ & $\mathrm{F}$ & $\mathrm{L}$ & $\mathrm{F}$ \\
\hline \multicolumn{5}{|l|}{ Rates of growth in year $1-500\left(\mathrm{~m} \mathrm{ka}^{-1} \mathrm{SLE}\right)$} \\
\hline Synchronous & 0.17 & 0.06 & 0.52 & 0.12 \\
\hline Asynchronous (1: 10) & 0.19 & 0.09 & 0.47 & 0.19 \\
\hline Kolmogorov statistic & 0.73 & 0.50 & 1.25 & 0.95 \\
\hline No albedo feedback $(1: 10)$ & & & 0.08 & 0.07 \\
\hline No topography feedback $(1: 10)$ & & & 0.45 & 0.11 \\
\hline \multicolumn{5}{|l|}{ Subsequent rates of growth $\mathrm{d} M / \mathrm{d} t\left(\mathrm{~m} \mathrm{ka}^{-1} \mathrm{SLE}\right)$} \\
\hline Years $1-5000(1: 10)$ & 0.22 & 0.08 & 0.55 & 0.17 \\
\hline Years $10000-30000(1: 100)$ & & & 0.16 & 0.15 \\
\hline Years $40000-50000(1: 100)$ & & & 0.04 & 0.06 \\
\hline \multicolumn{5}{|l|}{ Ice mass $M$ after various times (m SLE) } \\
\hline Year $10000(1: 10)$ & & & 3.9 & 1.6 \\
\hline Year $25000(1: 10)$ & & & 6.3 & 3.8 \\
\hline Steady state $(1: 100)$ & & & 8.8 & 6.2 \\
\hline Steady state $(1: 10)$ no albedo feedback & & & 0.5 & 0.3 \\
\hline Steady state $(1: 10)$ no topography feedback & & & 2.6 & 0.2 \\
\hline Steady state $(1: 10)$ & 2.6 & 0.7 & & \\
\hline
\end{tabular}

compare the distributions of the $500 S_{\mathrm{s}}$ values with the $50 S_{\mathrm{a}}$ values. We assume the values within each set to be independent, because the lag-1 autocorrelation in the $S$ timeseries is insignificant at the $5 \%$ level. We compare the $S_{\mathrm{s}}$ and $S_{\mathrm{a}}$ distributions for the four cases (two domains and two climates) using the Kolmogorov-Smirnov test, and in each case we accept the null hypothesis that the distributions are the same at the $5 \%$ significance level, for which the critical value (not to be exceeded) is 1.36 (Table 2). Hence we do not have statistically significant evidence that the evolution of $M$ during the first $500 \mathrm{yr}$ is different with synchronous and asynchronous coupling. On this basis, we consider it is acceptable to use asynchronous coupling to enable longer experiments.

\subsection{Steady-state ice-sheets for the recent climate}

When the asynchronous experiment for the recent climate is continued, Glimmer reaches a steady state in the Laurentide domain after about $30 \mathrm{ka}$ and in the Fennoscandian after $20 \mathrm{ka}$ (green in Fig. 5), with ice volumes of $1.01 \times 10^{6}$ and $0.30 \times 10^{6} \mathrm{~km}^{3}$ respectively (sea-level equivalent shown in Table 2). These are orders of magnitude greater than the real present-day masses of about $80 \times 10^{3}$ and $200 \mathrm{~km}^{3}$ in the Canadian Arctic and Scandinavia, respectively (Radić and Hock, 2010). In the FAMOUS-Glimmer simulation, an ice cap with a maximum thickness of $2200 \mathrm{~m}$ occupies south- ern Norway and Sweden, and most of the Canadian Arctic islands are covered with ice, with the greatest thickness of $2000 \mathrm{~m}$, on Baffin Island.

To test whether the excessive ice mass is due to the cold bias at high northern latitudes in the FAMOUS recent climate simulation, we ran Glimmer uncoupled from the climate model and compared results with input from either the FAMOUS or the HadSM3 simulation of recent climate. As mentioned above, the HadSM3 climate has considerably smaller biases, being warmer than the FAMOUS climate in the annual-mean by $2.5-5^{\circ} \mathrm{C}$ over Fennoscandia and $2-4{ }^{\circ} \mathrm{C}$ over Laurentia. Nonetheless, in both domains the uncoupled Glimmer equilibrium ice mass is larger with the HadSM3 climate than the FAMOUS climate. This is because HadSM3 has a smaller amplitude of seasonal cycle, producing less ablation in summer, and it illustrates the sensitivity to the approximations by the SMB scheme.

We conclude that the excessive ice volume simulated by FAMOUS-Glimmer for the recent climate is due to biases both from the SMB scheme and from the simulated climate. The latter may provide the additional cooling which Otieno and Bromwich (2009) found to be necessary for inception in Laurentia and Born et al. (2010) in Fennoscandia. In view of these biases, our simulations of the incipient glacial very likely also have biases. The approximations made by the 


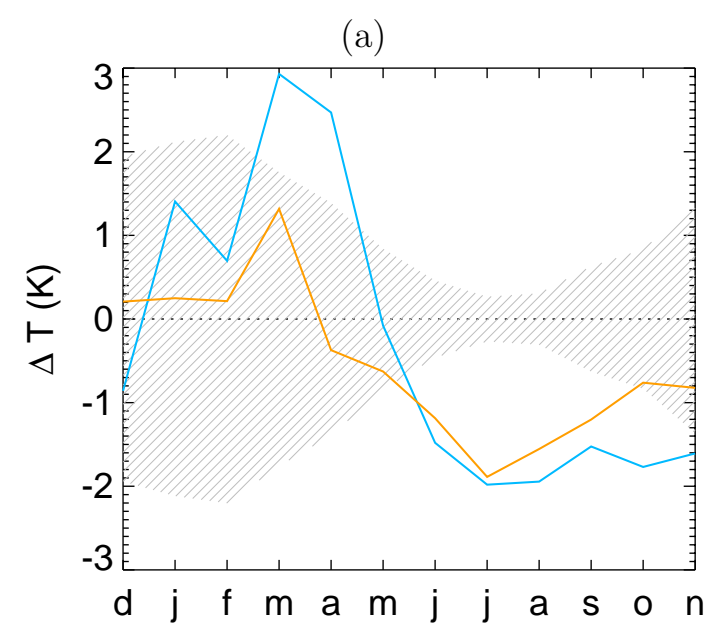

(b)

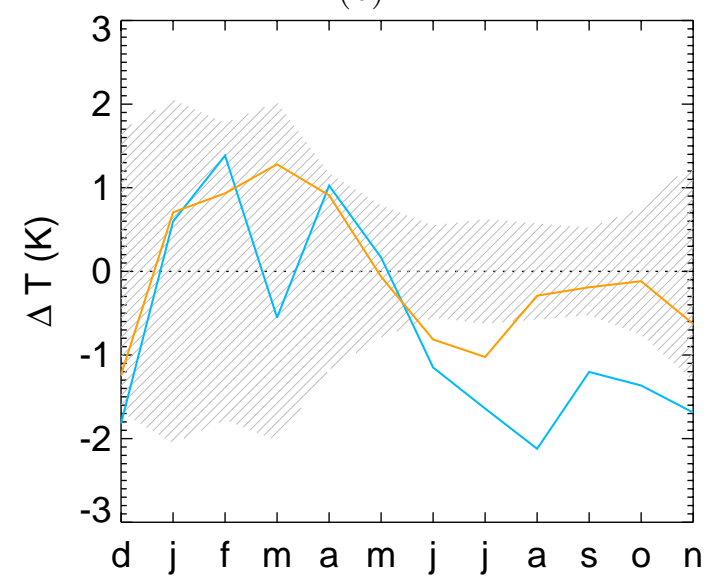

Fig. 4. Area-average difference in (a) Laurentia and (b) Fennoscandia of surface air temperature between incipient glacial and recent monthly climatology as simulated by FAMOUS (blue) and HadSM3 (orange) (IG minus recent). Hatching indicates statistically insignificant differences.

present versions of FAMOUS and Glimmer mean that we probably cannot accurately reproduce the real evolution of the ice-sheets at the start of the last glacial period. However, our interest is principally in studying the ice-sheet-climate interactions, and we think that the physical processes implicated in these interactions are likely to be reasonably well represented by the model, keeping in mind that the albedo feedback is exaggerated by design (Sect. 3.3).

\subsection{Approach to steady state in the incipient glacial climate}

Ice builds up initially on the islands in Laurentia, which are the highest regions and where ice caps are found at the present day, especially along the east coast of Baffin Island (Fig. 6). The mainland remains ice-free, except for the Keewatin region, on the north-west coast of the Hudson Bay. The areas of positive SMB (Fig. 7a) are relatively cold, and the

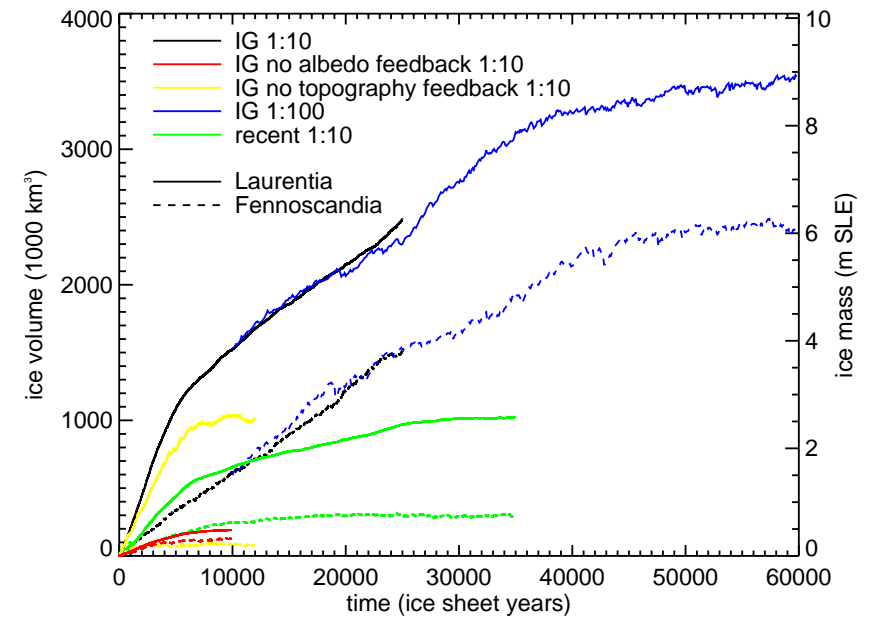

Fig. 5. Ice-sheet mass as a function of time through the whole length of the asynchronous $(1: 10$ and $1: 100)$ experiments. Glimmer domains are indicated by linestyle, and experiments by colour. Values are $100-$ yr means.

pattern is similar to that simulated by Otieno and Bromwich (2009) for the climate of $116 \mathrm{ka}$ BP. Ice-free areas where the potential for ablation exceeds the accumulation do not acquire ice cover, and hence by definition have zero SMB in the time-mean. After $500 \mathrm{yr}$, the largest Laurentide ice thickness, of $240 \mathrm{~m}$, is on eastern Baffin Island. In Fennoscandia the largest thickness is $550 \mathrm{~m}$, situated in southern Norway (Fig. 6), as found by Born et al. (2010). This area has positive SMB (Fig. 7b) due to high precipitation. In both domains, the distribution of ice thickness is very similar with the two coupling methods (Fig. 6).

The total ice mass in both domains continues to grow at approximately its initial rate of $0.7 \mathrm{~m} \mathrm{ka}^{-1}$ SLE during the first few millennia of the incipient glacial asynchronous experiment, after which the rate of growth declines (Table 2, Fig. 5). Caputo (2007) compares 12 reconstructions of global-mean sea-level change covering the last several glacial cycles. They indicate a sea-level fall of roughly 20 $70 \mathrm{~m}$ during $120-100 \mathrm{ka}$ BP i.e. $1.0-3.5 \mathrm{~m} \mathrm{ka}^{-1}$. There are a number of possible reasons why the simulated rate falls substantially short of the lowest reconstructed rate. First, icesheets were probably growing in other regions as well, such as Alaska, the Rockies and Siberia (e.g. Kageyama et al., 2004; Bonelli et al., 2009; Ganopolski et al., 2010). Second, the fixed sea-level in the experiments means that ice cannot cross the channels between the Canadian islands and the mainland or invade the Baltic Sea, and this limits the extent and build-up of the ice-sheets; we do not compute sealevel interactively because we are not modelling ice-sheets globally. Third, as discussed, there is a large systematic uncertainty in the simulation of ablation by the PDD scheme. We note at the start of our experiment that the total precipitation falling on the areas finally occupied by ice-sheets is 
(a)

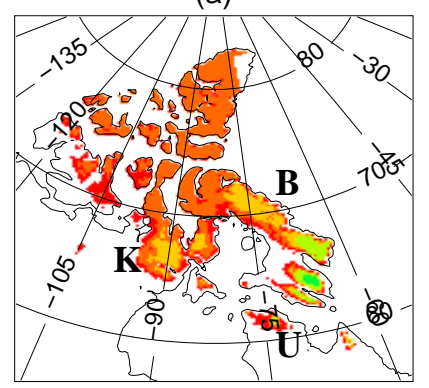

(c)

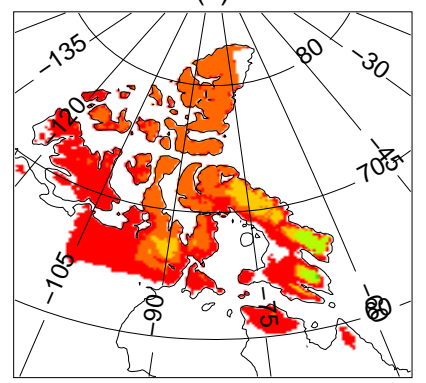

Asynchronous

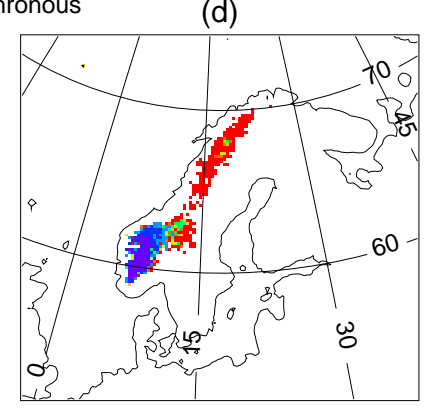

$50 \quad 100150200250300400 \quad 450$

Fig. 6. Ice-sheet time-mean thickness (m) in years 401-500 of the (a, b) synchronous and (c, d) asynchronous simulations for the incipient glacial climate. The letters in $(\mathbf{a}, \mathbf{b})$ indicate the locations of the Keewatin region, Baffin Island, the Ungava Peninsula, Norway, Sweden and Finland.

about $5 \mathrm{~m} \mathrm{ka}^{-1}$ SLE (Sect. 5.2), which gives an upper limit on the accumulation of ice mass that exceeds the highest reconstructed rate.

Within the first $10 \mathrm{ka}$, the ice caps on the eastern Canadian Arctic islands reach a steady state, and ice growth continues only in the Keewatin region and on the Ungava Peninsula (Fig. 8a, c). The most rapid growth in Fennoscandia initially occurs in the south of Norway and Sweden, but after about $10 \mathrm{ka}$ the southern ice cap approaches a steady state (Fig. 8b), while the northern ice cap starts to grow more quickly.

At $10 \mathrm{ka}$ an asychronously coupled experiment with an acceleration of 100 for ice-sheet time was begun; it shows greater variability, but a similar trend, to the $1: 10$ experiment, which was continued to $25 \mathrm{ka}$. After $20 \mathrm{ka}$ the northern ice cap of Fennoscandia becomes joined to the southern ice cap and begins to extend a lobe eastwards as well (Fig. 8d). After $30 \mathrm{ka}$ this lobe develops into a separate eastern dome, which expands over Finland to become the largest part of the ice-sheet, with a maximum thickness of $2700 \mathrm{~m}$ (Fig. 8f). After $40 \mathrm{ka}$, the Keewatin ice-sheet in Laurentia has attained its maximum extent, but it continues to thicken slowly for some further millennia, reaching a maximum thickness of $3200 \mathrm{~m}$ (Fig. 8e). The ice-sheets reach a steady state after about $50 \mathrm{ka}$ (Fig. 5, Table 2). (a) Years 1-100 (synchronous)

(b)
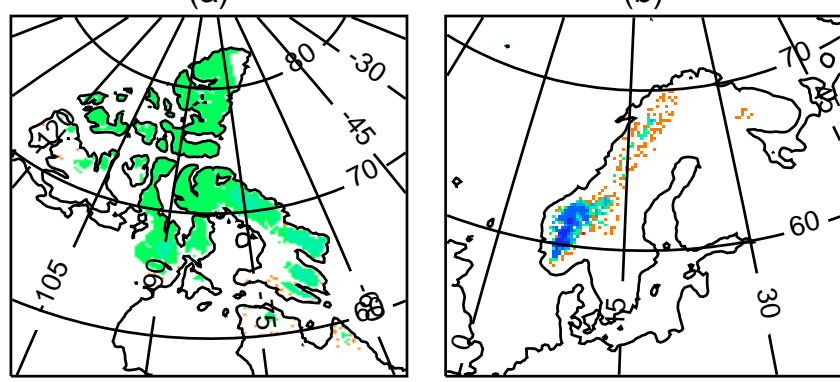

(c) Years $9001-10000(1: 10)$

(d)
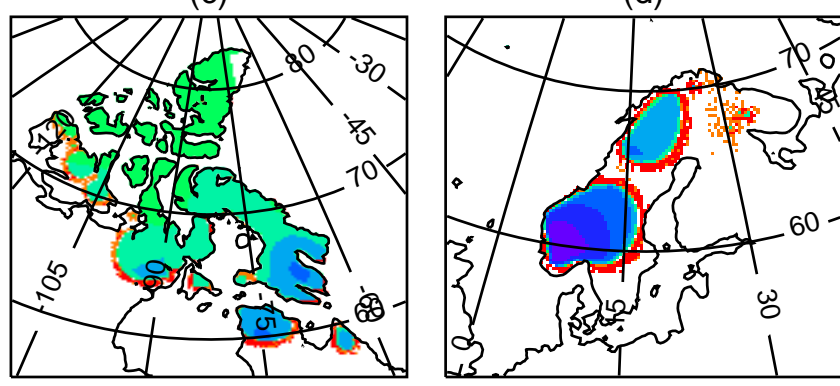

(e)

Steady state $(1: 100)$

(f)
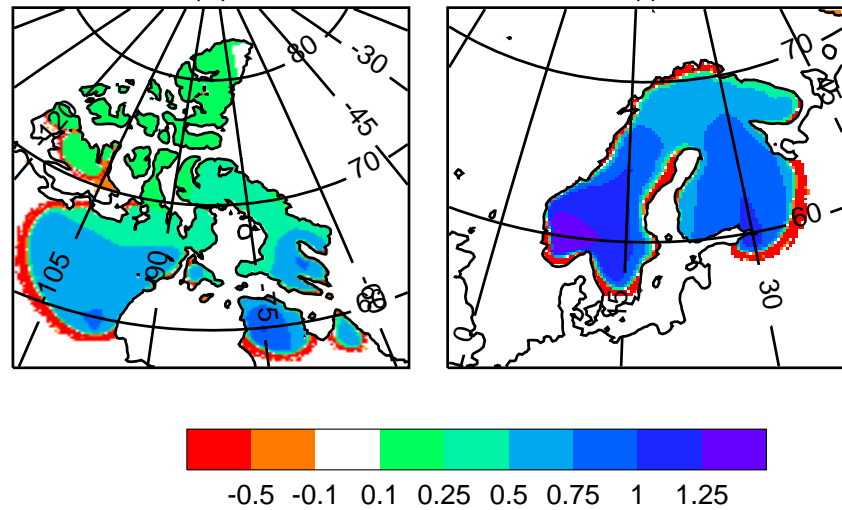

Fig. 7. Glimmer surface mass balance $\left(\mathrm{m} \mathrm{a}^{-1}\right.$ liquid water equivalent) for the time-means indicated in the incipient glacial climate.

The changes over time in the geographical pattern of icesheet growth suggest the influence of local climate feedbacks, which are the subject of the next section. In the same way, it is likely that further ice growth in Laurentia and Fennoscandia would be promoted by the local climate change caused by the growth of other ice-sheets outside these domains. In addition to local feedbacks, the fall in the atmospheric $\mathrm{CO}_{2}$ concentration and the increase in surface albedo, due to ice-sheet expansion during the glacial period, tended to cool the global climate (shown for FAMOUS by Smith and Gregory, 2012). 
(a) Years $9901-10000(1: 10)$
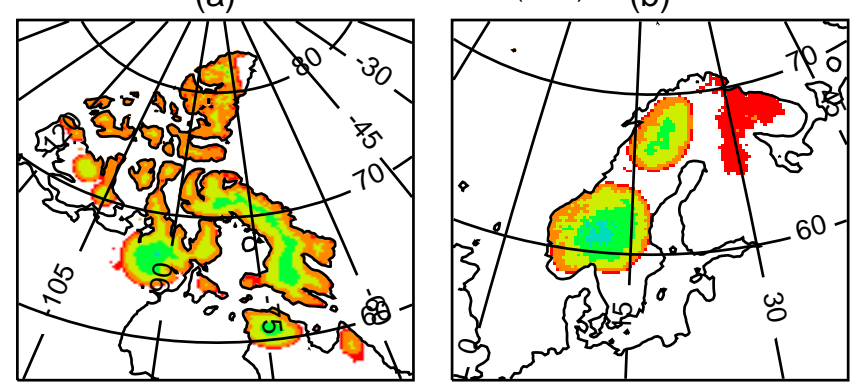

(c) Years $24901-25000(1: 10)$

(d)
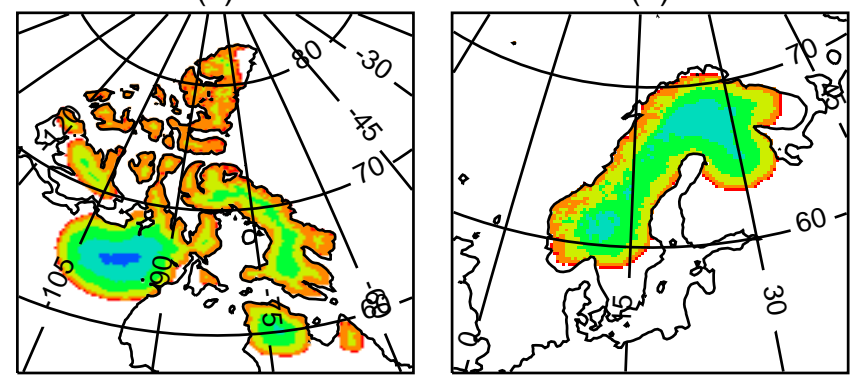

(e)

Steady state $(1: 100)$
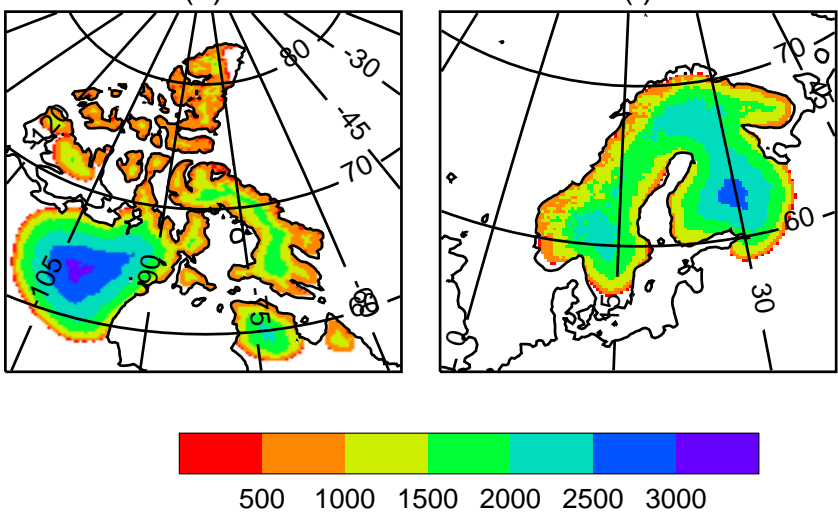

Fig. 8. Ice-sheet thickness (m) (a, b) after $10 \mathrm{ka},(\mathbf{c}, \mathbf{d})$ after $25 \mathrm{ka}$ and $(\mathbf{e}, \mathbf{f})$ in the steady state for the incipient glacial climate.

\section{Climate feedback on incipient glacial ice-sheets}

\subsection{Regional climate change}

Substantial areas are converted to ice-sheet surface characteristics in FAMOUS within the first two decades of the incipient glacial experiments (Sect. 4.1); this occurs in all FAMOUS gridboxes in which Glimmer anywhere shows positive SMB. The affected area is delimited by the green line in Figs. 9 and 10, and is defined as all the FAMOUS land gridboxes in Laurentia and Fennoscandia which have icesheet surface type for at least $10 \%$ of years during the first century of the synchronous experiment. The change of surface type produces a marked increase in surface albedo, by an average of 0.16 over the affected area, in the difference in the time-means for the first century between the

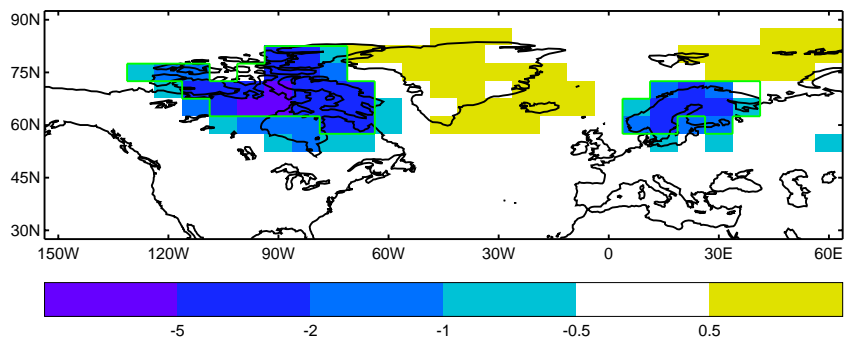

Fig. 9. Difference in the time-means for years 1-100 of surface air temperature $(K)$ between the synchronous FAMOUS-Glimmer experiment and the FAMOUS-only experiment under incipient glacial ("with Glimmer" minus "without Glimmer"). The green line shows the extent of the ice-sheet in FAMOUS during these years, as defined in the text.

synchronous FAMOUS-Glimmer experiment and the corresponding FAMOUS-only experiment. The albedo increase causes a reduction in absorbed solar radiation at the surface, by $14 \mathrm{~W} \mathrm{~m}^{-2}$ in the annual average in the affected area, which is comparable with the orbital forcing in summer. This in turn produces an annual average cooling of $2.7 \mathrm{~K}$ (Fig. 9) within the affected area, and the cooling also extends outside that area, i.e. the incipient ice-sheets influence the climate of the surroundings. The albedo feedback thus provides a mechanism for rapid extension of the ice-sheet area (Calov et al., 2009), which is maximised by the coupling scheme of FAMOUS-Glimmer (Sect. 3.3).

The small warming over the North Atlantic, Greenland and the Barents Sea (Fig. 9) could be caused by the strengthening of 1-2 Sv, which occurs in the Atlantic meridional overturning circulation. This in turn could be a response to colder air blowing over the north Atlantic from Laurentia (Hewitt et al., 2001; Smith and Gregory, 2012). In our model, unlike in that of Born et al. (2010), a decline in oceanic heat transport into the Nordic Seas is not a precondition for ice-sheet growth in Scandinavia.

In the final steady state there is a more complex picture of changes. Where the ice thickness is greatest (Keewatin, southern Norway, Finland, Fig. 8e, f), there is further cooling (Fig. 10a) on account of their surface elevation, and cloudiness and precipitation increase (Fig. 10b), feedbacks which all tend to promote ice-sheet growth. However, there is warming relative to the first century in various other parts of the Northern Hemisphere, mitigating some of the initial cooling. (Note that all areas occupied by the ice-sheets are still cooler than in the incipient glacial FAMOUS-only climate.)

This is because the appearance of the ice-sheets causes a substantial perturbation to the tropospheric circulation (Fig. 11). The North Atlantic is affected by a large anticyclonic anomaly centred over Baffin Island, with a secondary maximum over northern Scandinavia. This feature weakens the zonal flow and the Icelandic low, and surrounding it there is anomalous descent in the mid-troposphere (positive 
(a) Surface air temperature $(\mathrm{K})$

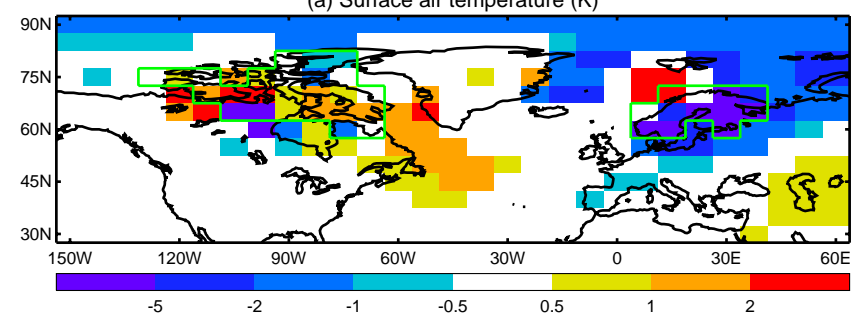

(b) Precipitation ( $\left.\mathrm{m} \mathrm{a}^{-1} \mathrm{LWE}\right)$

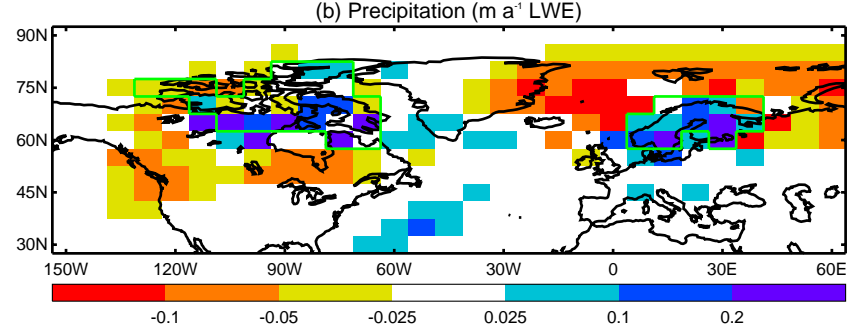

(c) Surface net downward solar radiation $\left(\mathrm{W} \mathrm{m}^{-2}\right)$

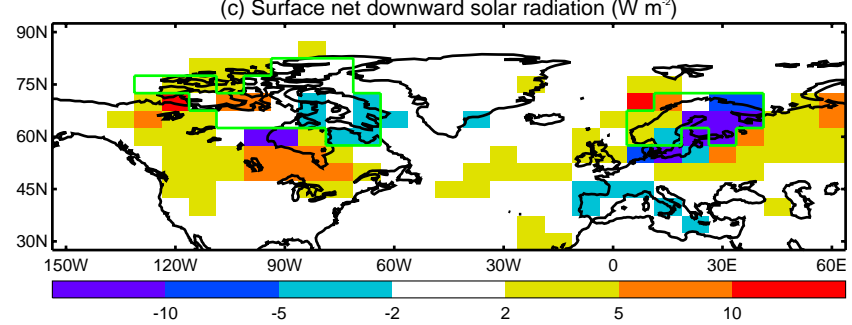

Fig. 10. Difference in the quantities indicated between the final steady state and the time-mean of years 1-100 of the synchronously coupled experiment for the incipient glacial climate (final minus initial). The green line shows the extent of the ice-sheet during years $1-100$, as defined in the text. Changes are shown only where they differ from internal variability, as determined by a two-tailed Student $t$-test at a significance level of $5 \%$.

$\omega$ amomaly) along the southern and western margins of the Laurentide ice-sheet and over the sea to the north-west of Scandinavia; the prevailing westerly flow produces anomalous descent to the east of the Fennoscandian ice-sheet as well. All these regions experience reduced cloudiness. The reduction in cloud gives increased solar radiation absorbed at the surface (Fig. 10c), which outweighs increases in surface albedo at the ice-sheet margins, accounts for the warming adjacent to the Laurentide ice-sheet, and is associated with a reduction in precipitation. Thus, the circulation changes induced by the Laurentide ice-sheet in particular tend to oppose its growth by warming and drying the climate in its lower portions and around its margins. Herrington and Poulsen (2012) describe a similar effect, whereby anomalous anticyclonic flow warms the southern and western margins of the expanding Laurentide ice sheet, giving a negative feedback on its growth.

The region to the east of the Fennoscandian ice-sheet has strongly reduced precipitation, being in its rain-shadow, and becomes cooler, despite increased insolation, presumably because of cold air advection. There is an anomalous cyclonic

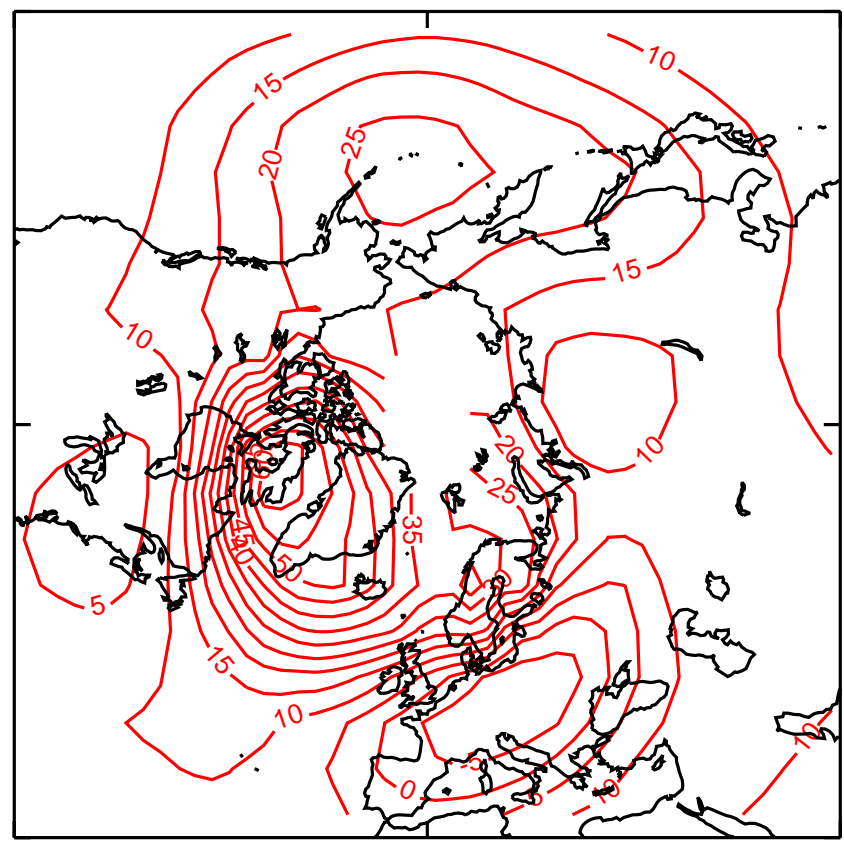

Fig. 11. Difference in $500 \mathrm{hPa}$ geopotential height (m) between the final steady state and the time-mean of years $1-100$ of the synchronously coupled experiment for the incipient glacial climate (final minus initial).

circulation over southern Europe, which brings increased cloudiness, precipitation and cooling. The areas of warming in the north-west Atlantic and the Norwegian Sea coincide with reductions of sea-ice. There is no significant change in the strength of the Atlantic meridional overturning circulation after the early decades of the experiment.

\subsection{Ice-sheet mass balance}

Cooling over the highest parts of the ice-sheets is enhanced in the Glimmer simulation due to greater elevation than the FAMOUS gridbox mean, and precipitation generally increases in these parts (Fig. 12). The consequences of these regional climate changes can be seen in the simulated changes in SMB (Fig. 7c-f). In some regions that initially have positive SMB, such as south-east Baffin Island, the north-east of the Keewatin region, and northern Norway, the SMB increases considerably. In many adjacent regions that initially have zero time-mean SMB, such as the Ungava Peninsula, most of the Keewatin region, Finland and southern Sweden, the SMB becomes positive and eventually large. Areas of negative SMB, where ice is converging dynamically, appear as narrow strips around the margins of the ice-sheets, such as on Greenland in the modern world.

SMB increases are dominated by the effect of cooling in reducing ablation, which in general outweighs reduction in precipitation. As an example of this, it is notable that the growth of the ice-sheet in Norway and Sweden reduces the 
(a) Years $9001-10000(1: 10)$
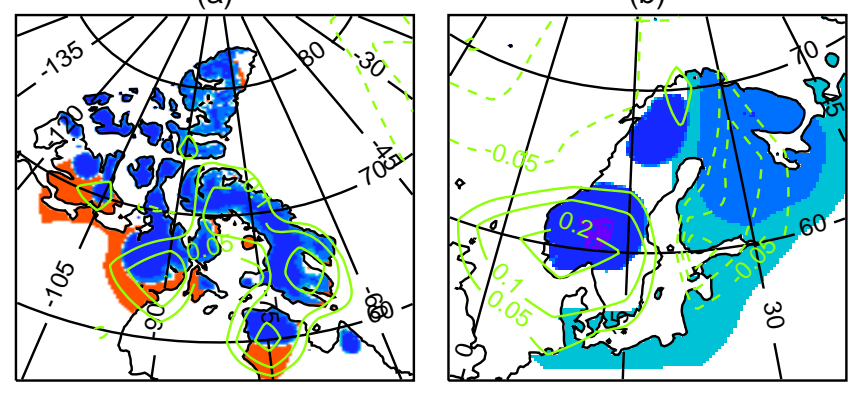

(c)
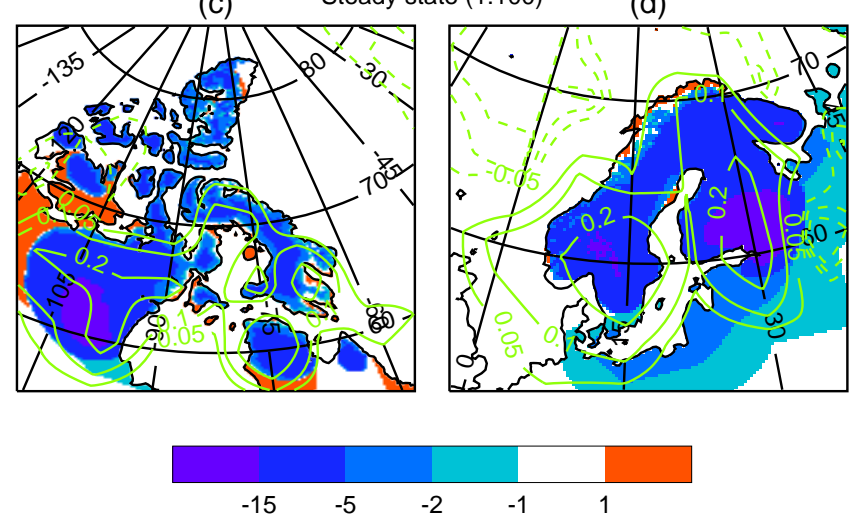

Fig. 12. Difference in the Glimmer surface air temperature $(\mathrm{K})$ between the time-means indicated and the time-mean of years 1-100 of the synchronously coupled experiment for the incipient glacial climate, shown by colours. Contour lines are superimposed showing the difference in precipitation $\left(\mathrm{m} \mathrm{a}^{-1}\right.$ liquid water equivalent).

precipitation in Finland (Fig. 12b), but this does not prevent a higher dome of the Fennoscandian ice-sheet from developing there, causing precipitation to increase again and the rain-shadow to move east (Fig. 12d).

In both domains, the area-integral SMB increases with time throughout the experiments (Fig. 13). Ice initially accumulates inland and there is no calving until the ice-sheets reach the coast, which happens in both domains after a couple of millennia. Thereafter calving becomes an important term in the budget. It increases more rapidly in Laurentia because the majority of the ice in the early stage is in ice caps on islands; later the rate of increase is slower while the icesheet is growing on the mainland. In both domains, the SMB reaches a steady value earlier than the calving flux. This suggests that it is the increase in calving, caused by continuing thickening of the ice-sheets, which finally limits their size.

A complementary picture (Fig. 14) is given by the components of mass balance shown as a function of ice-sheet area. In Fennoscandia, accumulation increases linearly with area. In Laurentia, there are different linear relationships in the early (island) and later (mainland) stages. This linearity indicates that local precipitation feedback (Fig. 10b) has a rather small influence. Ablation also increases with area, but not linearly: in Fennoscandia it decelerates, while in Laurentia (a) Laurentia

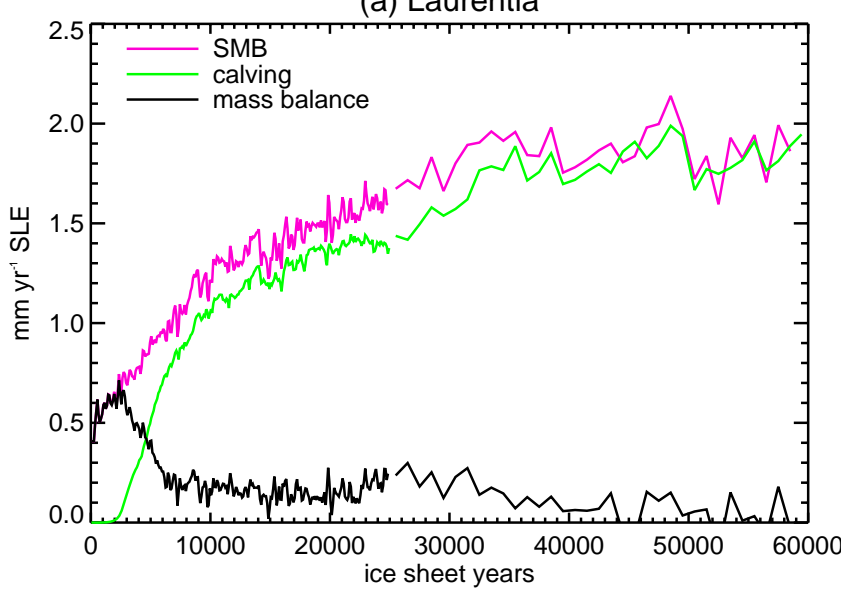

(b) Fennoscandia

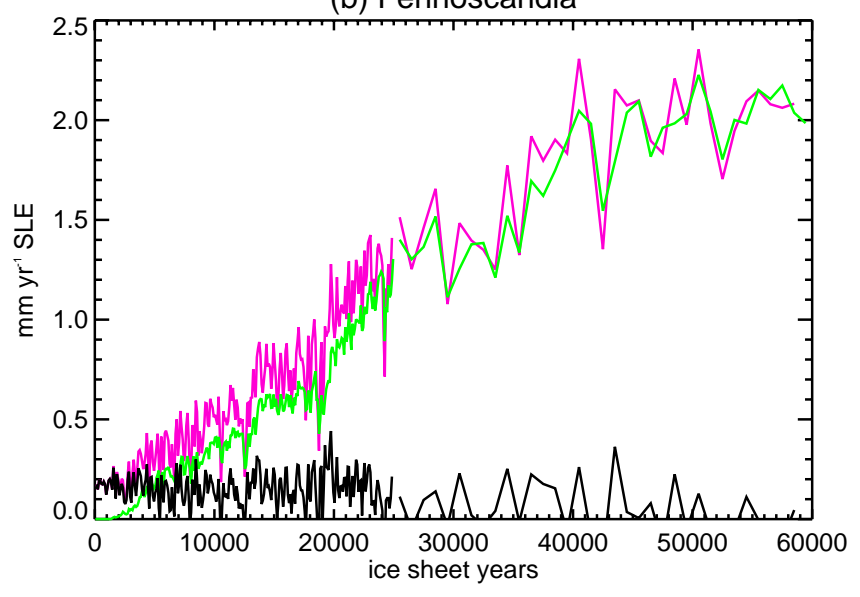

Fig. 13. Components of ice-sheet mass balance in the incipient glacial experiments shown as timeseries of area-integrals over the final ice-sheet area in each domain. The first $25 \mathrm{ka}$ of the timeseries are 100-yr means from the $1: 10$ experiment, the remainder are 1000-yr means from the $1: 100$ experiment.

it accelerates. This suggests that local temperature feedback is important in the marginal zone, where ablation mainly occurs, with opposite signs in the two domains.

In Fennoscandia, calving and ice-sheet mass both rise fairly linearly with ice-sheet area. In Laurentia, there is again more than one stage. Initially the area expands rapidly, owing to the surface albedo change, but the ice is thin. Next there is a thickening with little expansion, as the ice caps grow on the islands. In the final stage, while the mainland ice-sheet is growing, mass and calving both increase quite steadily with area, as in Fennoscandia. Theoretical considerations suggest a power-law relationship $M=A^{\gamma}$ between mass and area $A$ for steady-state ice caps, with $\gamma=1.25$ (Radić and Hock, 2010). Excluding the early stages, our Glimmer simulations give $\gamma=1.8$ for Laurentia and $\gamma=1.2$ for Fennoscandia. 
(a) Laurentia

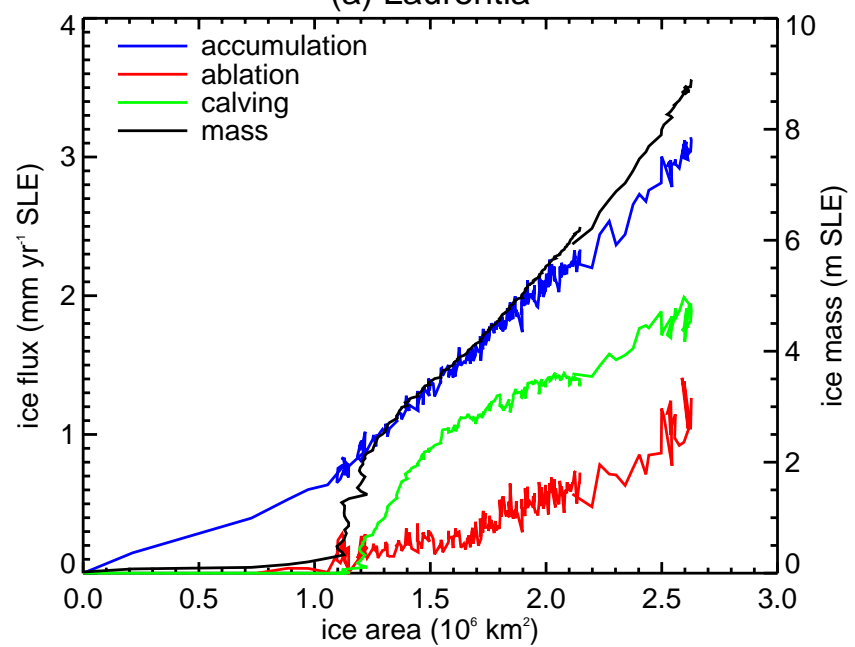

(b) Fennoscandia

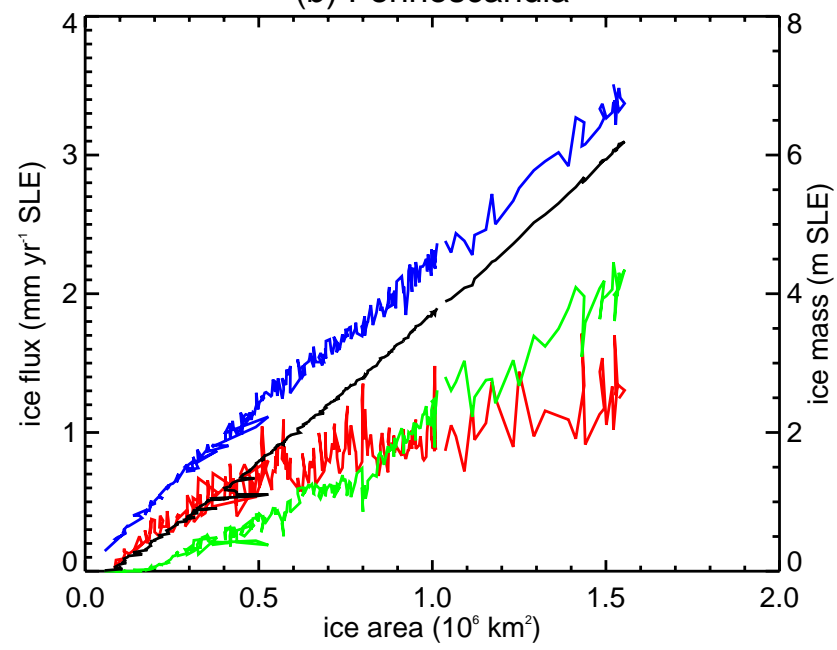

Fig. 14. Components of ice-sheet mass balance in the incipient glacial experiments integrated over the time-dependent ice-sheet area in each domain and shown as functions of that area. The first $25 \mathrm{ka}$ of the timeseries are 100-yr means from the $1: 10$ experiment, the remainder are 1000-yr means from the $1: 100$ experiment.

\subsection{Sensitivity experiments for climate feedback on SMB}

We separate the effects of albedo and topography on SMB by carrying out two further experiments in which they are separately suppressed. These integrations are asychronously coupled $(1: 10)$ and begin from the same starting state as the other incipient glacial simulations.

In one experiment, we suppress the albedo feedback on ice-sheet growth by not updating the snow-free albedo in the FAMOUS-Glimmer coupling. The initial $\mathrm{d} M / \mathrm{d} t$ is much smaller in this experiment than in the fully coupled experiment (Fig. 5 and Table 2), because the area of positive SMB is much less from the outset, and expands little. A steady state

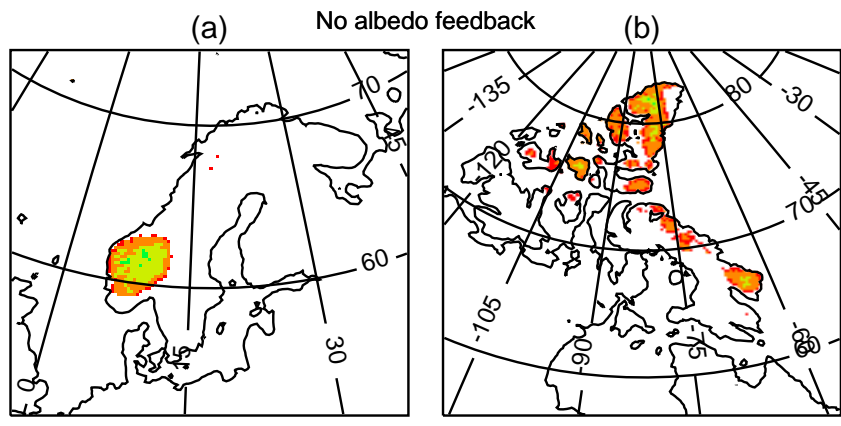

(c) No topography feedback

(d)
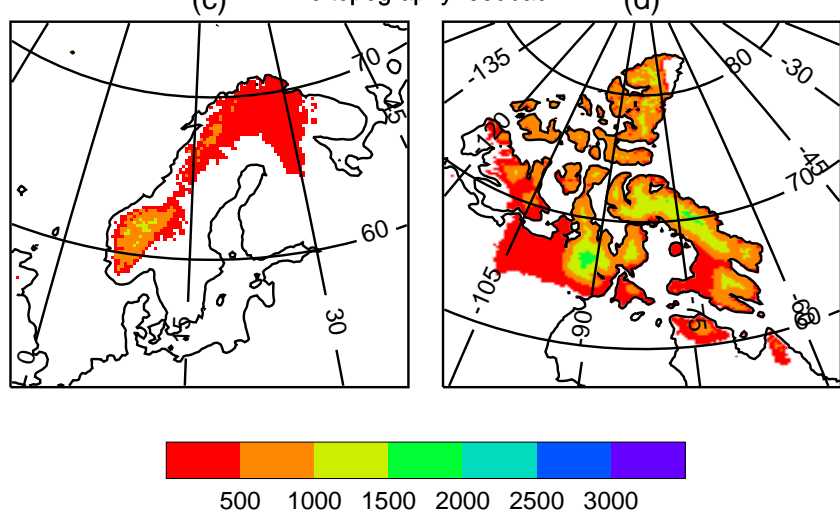

Fig. 15. Ice-sheet time-mean thickness $(m)$ in the steady state for the incipient glacial climate (a, b) without albedo feedback, $(\mathbf{c}, \mathbf{d})$ without topography feedback.

is reached in both domains in less than $10 \mathrm{ka}$, with $M$ about 20 times smaller in each domain than in the fully coupled steady state (Table 2), and with ice in both cases mostly restricted to its initial areas of growth (Fig. 15a, b). This experiment indicates that the albedo feedback promotes ice-sheet development by expanding the area of positive SMB. The ice-sheet margin can advance thereby more rapidly than by ice dynamics; indeed, it appears that the ice-sheets cannot spread far by dynamics alone.

In the other experiment, we suppress elevation feedbacks by (i) keeping the FAMOUS surface topography unchanged as the Glimmer ice-sheet surface topography evolves; (ii) using the Glimmer bedrock topography, i.e. its initial surface topography, instead of the Glimmer actual surface topography, for the lapse-rate adjustment in the temperature interpolation. Thus, as far as climate and SMB are concerned, surface topography does not change as the ice-sheets grow. With this design, we cannot distinguish the effect of elevation on local climate from the effect of topography on regional climate. In reality, these two are not clearly separable, but one might think that we could suppress the latter and keep the former by doing (i) but not (ii). However, an increasingly large adjustment using the assumed lapse-rate would then be applied to convert FAMOUS surface temperature to Glimmer surface temperature as the two surfaces became further apart. 
The results would be very sensitive to the lapse rate and we do not think they would be physically reliable.

In this experiment, $\mathrm{d} M / \mathrm{d} t$ is initially similar to the fully coupled experiment (Fig. 5 and Table 2). It is not surprising that the elevation feedback has no effect initially, because it takes time for ice to build up. Within the first millennium, however, $M$ falls behind without elevation feedback, and in less than $10 \mathrm{ka}$ reaches a steady state 3 times smaller in Laurentia than in the fully coupled steady state, and 9 times smaller in Fennoscandia (Table 2). Thus it appears that the topography feedback is eventually important in our experiments, in contrast to the results of Kageyama et al. (2004). Without the topography feedback (Fig. 15c, d), the ice-sheets remain rather thin, and they do not expand so far into the Keewatin region and Finland, suggesting that ice dynamics plays a role here.

Neither of the experiments achieve ice-thickness as great as in the fully coupled experiment, even in areas that initially have positive SMB. For instance, the final thickness on Baffin Island is $1200 \mathrm{~m}$ without albedo feedback and $1700 \mathrm{~m}$ without topography feedback, compared with $2000 \mathrm{~m}$ with both feedbacks; in southern Scandinavia, the corresponding figures are 1800, 1300 and 2400. The final area of positive SMB in each domain in the fully coupled experiment is also greater. The total $M$ in each domain with both feedbacks exceeds the sum of the totals obtained with each separately.

\section{Conclusions}

We have coupled the FAMOUS global AOGCM to the Glimmer thermomechanical ice-sheet model in order to simulate the coevolution of climate and ice-sheets following glacial inception in two domains: north-east America (Laurentia) and north-west Europe (Fennoscandia). This is the first use of a coupled AOGCM-ice-sheet model for a study on long palæoclimate timescales. Our purpose is to investigate the interaction between ice-sheets and climate, rather than to obtain a comprehensive simulation of the glacial cycle, and to this end we fix the boundary conditions of orbital forcing, atmospheric composition and sea-level.

In the coupled model, ice-sheet surface mass balance (SMB) is derived from the surface climate; surface topography and other surface characteristics of the climate model are updated as the ice-sheet extent and thickness changes. For ice-sheet surface ablation we use a positive-degree-day method, a commonly used empirical scheme. Owing to the approximations and possible biases in this scheme-probably exacerbated by the cold bias in the model climate in high northern latitudes-substantial ice caps, not present in the modern world, develop in FAMOUS-Glimmer simulations of recent (pre-industrial) climate. While noting that these errors make our simulation of ice-sheet growth less realistic, we nonetheless consider the model adequate for our purpose.
With the orbital forcing of $115 \mathrm{ka} \mathrm{BP}$, late summer is cooler than in the recent climate at high northern latitudes. Such conditions favour glacial inception, and FAMOUSGlimmer initially produces ice caps on the Canadian Arctic islands, on the north-west coast of the Hudson Bay, and in southern Scandinavia. These subsequently grow to occupy the Keewatin region of the Canadian mainland and all of Fennoscandia. Once the ice-sheets reach the coast they begin to discharge ice into the sea, at a rate which increases as the ice-sheet thickens, and this eventually halts their growth after about $50 \mathrm{ka}$. This important role for ice outflow indicates that a realistic simulation of ice-sheet evolution during the last glacial cycle will be sensitive to the treatment of the grounding line, ice-shelves and sea-level change. Attention to these aspects is a requirement, in particular for simulating the advance of ice into the channels between the Canadian islands and over the Baltic Sea, without which the growth of the ice-sheets is unrealistically restrained.

The expansion of the ice-sheets influences the regional climate, which becomes cooler; over the ice-sheet areas, this cooling is larger than that produced by the orbital forcing. The cooling reduces the ablation, and ice accumulates in places that initially do not have positive SMB, such as the Ungava Peninsula. The results suggest the possibility that the glaciation of north-east America could have begun on the Canadian Arctic islands, producing a regional climate change that caused or enhanced the growth of ice on the mainland. The experiments show that the feedbacks on SMB from topography change and change in surface albedo (due to change in snow and ice cover) reinforce each other in promoting the increase of ice-sheet thickness and the expansion of area.

The albedo feedback is dominant regarding the area of the ice-sheets, and acts rapidly. We have exaggerated the effect of this feedback by assigning ice-sheet characteristics to any FAMOUS gridbox in which Glimmer accumulates ice, even though FAMOUS gridboxes are much larger. By contrast, when we suppress the albedo feedback altogether, the icesheets are mostly restricted to their initial areas of positive SMB and their final mass is an order of magnitude smaller.

The feedback of topography on SMB does not become significant for several centuries, after which it begins to affect the further thickening of the ice-sheets. In addition, the growth of the ice-sheets causes a substantial perturbation to the tropospheric circulation, with various effects on Northern Hemisphere climate. In particular, it produces some reduction of cloud and consequent warming along the margin of the Laurentide ice-sheet, which mitigates the local cooling due to expansion of snow cover.

Compared with EMICs previously used coupled climateice-sheet models, FAMOUS has a more detailed, physically based representation of relevant climate processes such as atmospheric circulation, precipitation and cloudiness. Using FAMOUS, we qualitatively confirm some previous conclusions and reveal further complexity. Our experiments 
demonstrate the importance of interactions between icesheets and climate in determining their evolution following glacial inception.

The results are sensitive to many model details, approximations and biases. It is evident that further model development is required to obtain a fully realistic simulation. In future work, we intend to unify the ice-sheet and AOGCM simulations of SMB by embedding in the AOGCM a land-ice surface model based on mass and energy balance, including refreezing and the effect of snow ageing on albedo. Compared with the model used in the present work, this treatment will be more self-consistent and less empirical. We will also implement fractional ice-sheet coverage in order to simulate the albedo feedback realistically, and the dependence of SMB on altitude within each AOGCM gridbox in order to remove the dependence on a prescribed lapse-rate (cf. Pritchard et al., 2008; Otieno and Bromwich, 2009; Vizcaíno et al., 2010; Fyke et al., 2011).

Acknowledgements. We are grateful for useful discussions with Robin Smith, Philippe Huybrechts, Glenn Milne and Rowan Sutton, for assistance from NCAS Computational Modelling Support, and for the comments of the two referees, which helped us to improve the paper. Oliver Browne's work was supported by a NERC PhD studentship. Jonathan Gregory's work was supported by the NCAS-Climate Programme and NERC grant NE/I011099/1.

Edited by: A. Paul

\section{References}

Abe-Ouchi, A., Segawa, T., and Saito, F.: Climatic Conditions for modelling the Northern Hemisphere ice sheets throughout the ice age cycle, Clim. Past, 3, 423-438, doi:10.5194/cp-3-423-2007, 2007.

Bonelli, S., Charbit, S., Kageyama, M., Woillez, M.-N., Ramstein, G., Dumas, C., and Quiquet, A.: Investigating the evolution of major Northern Hemisphere ice sheets during the last glacialinterglacial cycle, Clim. Past, 5, 329-345, doi:10.5194/cp-5-3292009, 2009.

Born, A., Kageyama, M., and Nisancioglu, K. H.: Warm Nordic Seas delayed glacial inception in Scandinavia, Clim. Past, 6, 817-826, doi:10.5194/cp-6-817-2010, 2010.

Braithwaite, R. J.: Positive degree-day factors for ablation on the Greenland ice-sheet studied by energy-balance modeling, J. Glaciol., 41, 153-160, 1995.

Brayshaw, D. J., Hoskins, B., and Black, E.: Some physical drivers of changes in the winter storm tracks over the North Atlantic and Mediterranean during the Holocene, Philos. Trans. R. Soc. London, 368, 5185-5223, doi:10.1098/rsta.2010.0180, 2010.

Browne, O. J. H.: Numerical modelling of large-scale ice-sheetclimate interactions, Ph.D. thesis, University of Reading, 2009.

Calov, R., Ganopolski, A., Claussen, M., Petoukhov, V., and Greve, R.: Transient simulation of the last glacial inception. Part I: glacial inception as a bifurcation in the climate system, Clim. Dynam., 24, 545-561, 2005.
Calov, R., Ganopolski, A., Kubatzki, C., and Claussen, M.: Mechanisms and time scales of glacial inception simulated with an Earth system model of intermediate complexity, Clim. Past, 5, 245-258, doi:10.5194/cp-5-245-2009, 2009.

Caputo, R.: Sea-level curves: Perplexities of an end-user in morphotectonic applications, Global Planet. Change, 57, 417-423, doi:10.1016/j.gloplacha.2007.03.003, 2007.

Charbit, S., Ritz, C., and Ramstein, G.: Simulations of Northern Hemisphere ice-sheet retreat: sensitivity to physical mechanisms involved during the Last Deglaciation, Quaternary Sci. Rev., 21, 243-265, doi:10.1016/S0277-3791(01)00093-2, 2002.

Charbit, S., Kageyama, M., Roche, D., Ritz, C., and Ramstein, G.: Investigating the mechanisms leading to the deglaciation of past continental northern hemisphere ice sheets with the CLIMBERGREMLINS coupled model, Global Planet. Change, 48, 253273, 2005.

Dong, B. W. and Valdes, P. J.: Sensitivity studies of northernhemisphere glaciation using an atmospheric general-circulation model, J. Climate, 8, 2471-2496, 1995.

EPICA Community Members: Eight glacial cycles from an Antarctic ice core, Nature, 429, 623-628, 2004.

Fyke, J. G., Weaver, A. J., Pollard, D., Eby, M., Carter, L., and Mackintosh, A.: A new coupled ice sheet/climate model: description and sensitivity to model physics under Eemian, Last Glacial Maximum, late Holocene and modern climate conditions, Geosci. Model Devel., 4, 117-136, doi:10.5194/gmd-4117-2011, 2011.

Ganopolski, A., Calov, R., and Claussen, M.: Simulation of the last glacial cycle with a coupled climate ice-sheet model of intermediate complexity, Clim. Past, 6, 229-244, doi:10.5194/cp-6-2292010, 2010.

Gardner, A. S. and Sharp, M.: Sensitivity of net mass-balance estimates to near-surface temperature lapse rates when employing the degree-day method to estimate glacier melt, Ann. Glaciol., 50, 80-86, 2009.

Gordon, C., Cooper, C., Senior, C. A., Banks, H., Gregory, J. M., Johns, T. C., Mitchell, J. F. B., and Wood, R. A.: The Simulation of SST, sea ice extents and ocean heat transports in a version of the Hadley Centre coupled model without flux adjustments, Clim. Dynam., 16, 147-168, 2000.

Gregoire, L. J., Valdes, P. J., Payne, A. J., and Kahana, R.: Optimal tuning of a GCM using modern and glacial constraints, Clim. Dynam., 37, 705-719, doi:10.1007/s00382-010-0934-8, 2011.

Herrington, A. R. and Poulsen, C. J.: Terminating the Last Interglacial: The Role of Ice Sheet-Climate Feedbacks in a GCM Asynchronously Coupled to an Ice Sheet Model, J. Climate, 25, 1871-1882, doi:10.1175/JCLI-D-11-00218.1, 2012.

Hewitt, C. D. and Mitchell, J. F. B.: Radiative forcing and response of a GCM to ice age boundary conditions: Cloud feedback and climate sensitivity, Clim. Dynam., 13, 821-834, 1997.

Hewitt, C. D., Broccoli, A. J., Mitchell, J. F. B., and Stouffer, R. J.: A coupled model study of the last glacial maximum: Was part of the North Atlantic relatively warm?, Geophys. Res. Lett., 28, 1571-1574, 2001.

Hewitt, C. D., Stouffer, R. J., Broccoli, A. J., Mitchell, J. F. B., and Valdes, P. J.: The effect of ocean dynamics in a coupled GCM simulation of the last glacial maximum, Clim. Dynam., 20, 203218, doi:10.1007/s00382-002-0272-6, 2003. 
Huybrechts, P.: Sea-level changes at the LGM from ice-dynamic reconstructions of the Greenland and Antarctic ice sheets during the glacial cycles, Quaternary Sci. Rev., 21, 203-231, 2002.

Huybrechts, P., Letreguilly, A., and Reeh, N.: The Greenland ice sheet and greenhouse warming, Palaeogeogr. Palaeocl., 89, 399412, 1991.

Huybrechts, P., Goelzer, H., Janssens, I., Driesschaert, E., Fichefet, T., Goosse, H., and Loutre, M.-F.: Response of the Greenland and Antarctic Ice Sheets to Multi-Millennial Greenhouse Warming in the Earth System Model of Intermediate Complexity LOVECLIM, Surv. Geophys., 32, 397-416, doi:10.1007/s10712-0119131-5, 2011.

Jones, C. D., Gregory, J. M., Thorpe, R. B., Cox, P. M., Murphy, J. M., Sexton, D. M. H., and Valdes, P.: Systematic optimisation and climate simulation of FAMOUS, a fast version of HadCM3, Clim. Dynam., 25, 189-204, doi:10.1007/s00382-005-0027-2, 2005.

Kageyama, M., Charbit, S., Ritz, C., Khodri, M., and Ramstein, G.: Quantifying ice-sheet feedbacks during the last glacial inception, Geophys. Res. Lett., 31, L24203, doi:10.1029/2004GL021339, 2004.

Khodri, M., Ramstein, G., de Noblet-Ducoudré, N., and Kageyama, M.: Sensitivity of the northern extratropics hydrological cycle to the changing insolation forcing at 126 and $115 \mathrm{ky} \mathrm{BP}$, Clim. Dynam., 21, 273-287, doi:10.1007/s00382-003-0333-5, 2003.

Lunt, D. J., de Noblet-Ducoudre, N., and Charbit, S.: Effects of a melted Greenland ice sheet on climate, vegetation, and the cryosphere, Clim. Dynam., 23, 679-694, doi:10.1007/s00382004-0463-4, 2004.

Marshall, S. J., James, T. S., and Clarke, G. K. C.: North American Ice Sheet reconstructions at the Last Glacial Maximum, Quaternary Sci. Rev., 21, 175-192, 2002.

Marshall, S. J., Sharp, M. J., Burgess, D. O., and Anslow, F. S.: Near-surface-temperature lapse rates on the Prince of Wales Icefield, Ellesmere Island, Canada: implications for regional downscaling of temperature, Int. J. Climatol., 27, 385-398, 2007.

Otieno, F. O. and Bromwich, D. H.: Contribution of Atmospheric Circulation to Inception of the Laurentide Ice Sheet at $116 \mathrm{kyr}$ BP, J. Climate, 22, 39-57, doi:10.1175/2008JCLI2211.1, 2009.

Payne, A. J.: A thermomechanical model of ice flow in West Antarctica, Clim. Dynam., 15, 115-125, 1999.

Pollard, D.: A retrospective look at coupled ice sheet-climate modeling, Clim. Change, 100, 173-194, doi:10.1007/s10584-0109830-9, 2010.

Pritchard, M. S., Bush, A. B. G., and Marshall, S. J.: Neglecting ice-atmosphere interactions underestimates ice sheet melt in millennial-scale deglaciation simulations, Geophys. Res. Lett., 35, L01503, doi:10.1029/2007GL031738, 2008.

Radić, V. and Hock, H.: Regional and global volumes of glaciers derived from statistical upscaling of glacier inventory data, J. Geophys. Res., 115, F01010, doi:10.1029/2009JF001373, 2010.
Reeh, N.: Parameterization of melt rate and surface temperature on the Greenland ice sheet, Polarforschung, 59, 113-128, 1989.

Reichler, T. and Kim, J.: How well do coupled models simulate Today's climate?, B. Am. Meteorol. Soc., 89, 303-311, doi:10.1175/BAMS-89-3-303, 2008.

Ridley, J., Huybrechts, P., Gregory, J. M., and Lowe, J. A.: Elimination of the Greenland ice sheet in a high $\mathrm{CO}_{2}$ climate, J. Climate, 18, 3409-3427, 2005.

Ridley, J., Gregory, J. M., Huybrechts, P., and Lowe, J.: Thresholds for irreversible decline of the Greenland ice sheet, Clim. Dynam., 35, 1065-1073, doi:10.1007/s00382-009-0646-0, 2010.

Rutt, I. C., Hagdorn, M., Hulton, N. R. J., and Payne, A. J.: The Glimmer community ice sheet model, J. Geophys. Res., 114, F02004, doi:10.1029/2008JF001015, 2009.

Smith, R. S. and Gregory, J. M.: Transient simulations of the last glacial cycle with an AOGCM, Clim. Dynam., 38, 1545-1559, doi:10.1007/s00382-011-1283-y, 2012.

Smith, R. S., Osprey, A., and Gregory, J. M.: A description of the FAMOUS (version XDBUA) climate model and control run, Geosci. Model Devel., 1, 53-68, doi:10.5194/gmd-1-53-2008, 2008.

Tarasov, L. and Peltier, W. R.: A calibrated deglacial drainage chronology for the North American continent: evidence of an Arctic trigger for the Younger Dryas, Quaternary Sci. Rev., 25, 659-688, 2006.

van den Broeke, M., Bus, C., Ettema, J., and Smeets, P.: Temperature thresholds for degree-day modelling of Greenland ice sheet melt rates, Geophys. Res. Lett., 37, L18501, doi:10.1029/2010GL044123, 2010.

Vettoretti, G. and Peltier, W. R.: Post-Eemian Glacial Inception. Part I: The impact of a Summer Seasonal Temperature Bias, J. Climate, 16, 889-911, 2003.

Vizcaíno, M., Mikolajewicz, U., Gröger, M., Maier-Reimer, E., Schurgers, G., and Winguth, A. M. E.: Long-term ice sheetclimate interactions under anthropogenic greenhouse forcing simulated with a complex Earth System Model, Clim. Dynam., 31, 665-690, doi:10.1007/s00382-008-0369-7, 2008.

Vizcaíno, M., Mikolajewicz, U., Jungclaus, J., and Schurgers, G.: Climate modification by future ice sheet changes and consequences for ice sheet mass balance, Clim. Dynam., 34, 301-324, doi:10.1007/s00382-009-0591-y, 2010.

Wang, Z. and Mysak, L. A.: Simulation of the last glacial inception and rapid ice sheet growth in the McGill paleoclimate model, Geophys. Res. Lett., 29, 2102, doi:10.1029/2002GL015120, 2002.

Yoshimori, M., Reader, M. C., Weaver, A. J., and McFarlane, N. A.: On the causes of glacial inception at $116 \mathrm{ka}$ BP, Clim. Dynam., 18, 383-402, 2002.

Zweck, C. and Huybrechts, P.: Modeling of the northern hemisphere ice sheets during the last glacial cycle and glaciological sensitivity, J. Geophys. Res., 110, D07103, doi:10.1029/2004JD005489, 2005. 